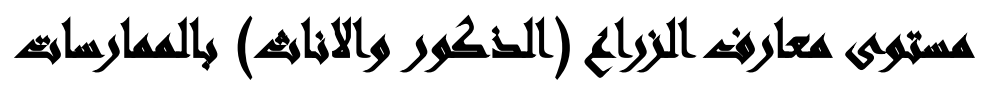

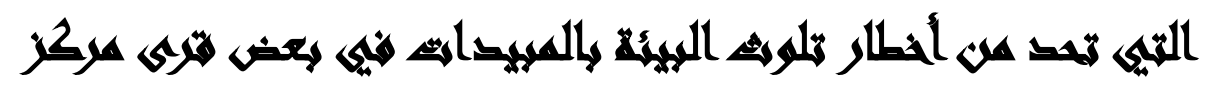

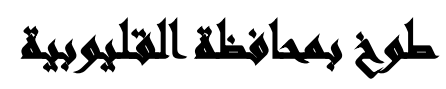

[Ir]

محمد السعيد صالح الزميتي(') - محمد نسيم علي سويلم(؟)-- محب محمود كامل الرافعي(r)

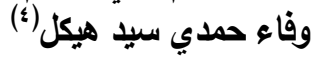

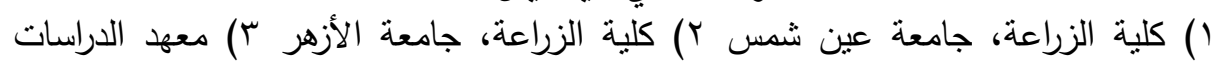

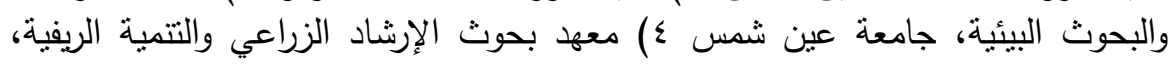
مركز البحوث الزراعية

\section{المستخلصن}

استهدف البحث التعرف على مستوى معارف المبحوثين(الذكور والإناث) بالتوصيات

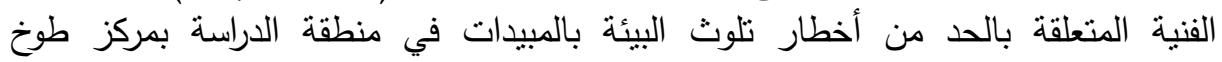

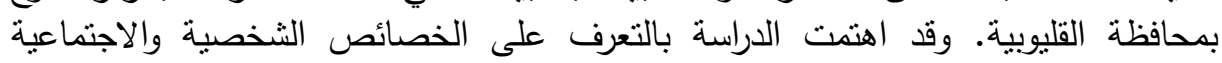

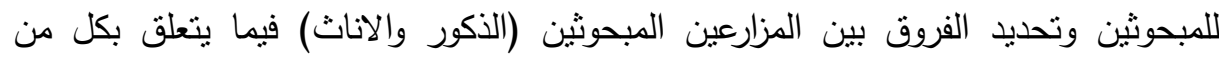

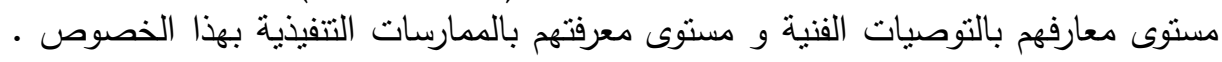

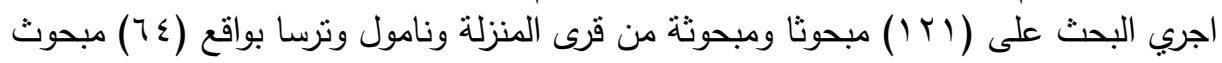

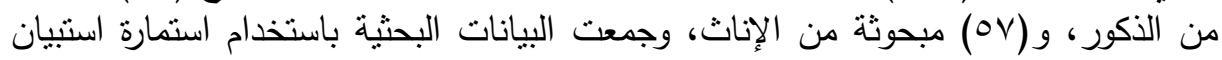

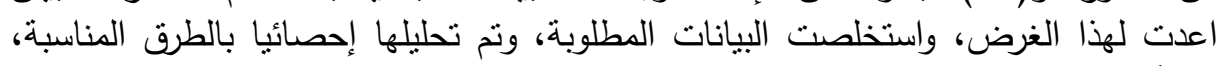

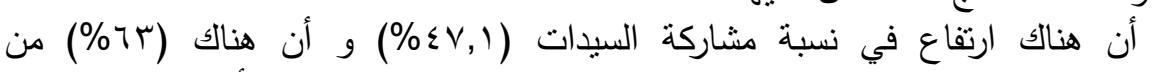
وقد أوضحت النتائج المتحصل عليها:

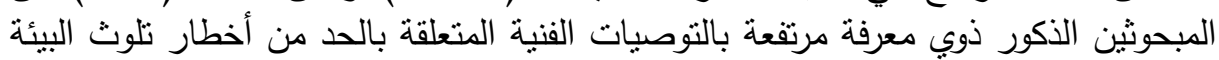

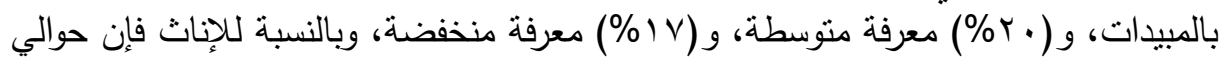

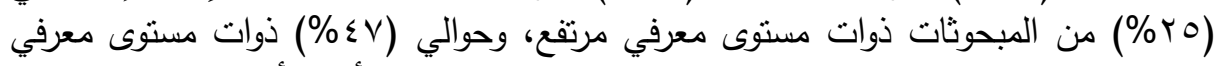

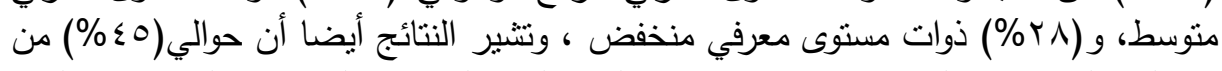

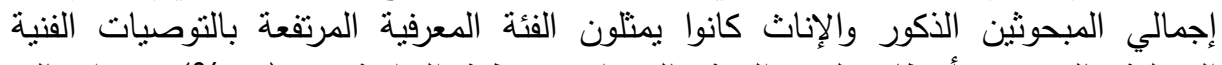

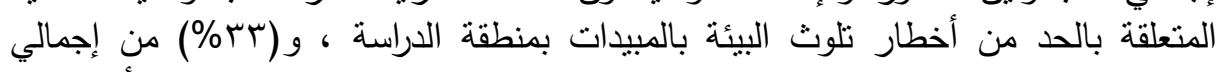

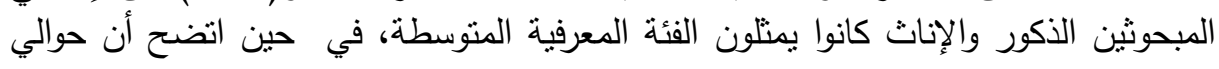

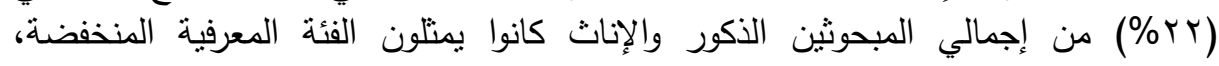

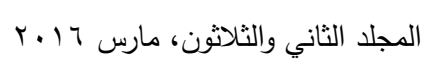




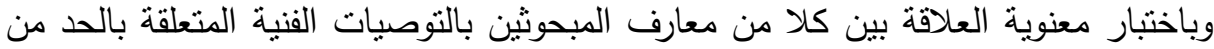

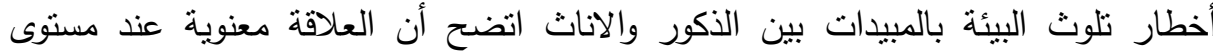

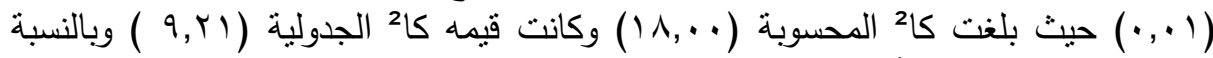
لتتفيذ التوصيات وجد أن هناك (00\%) من المبحوثين الذكور ينفذون بدرجة مرتفعة،

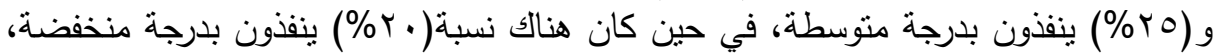

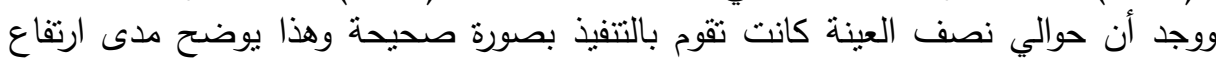

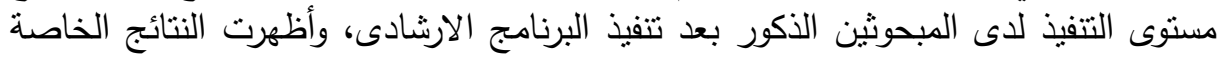

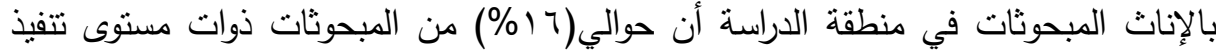

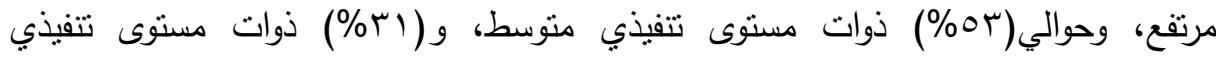

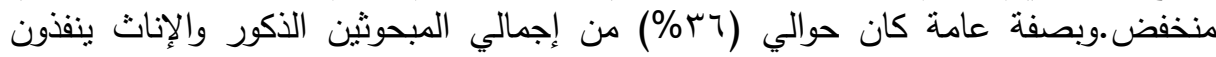

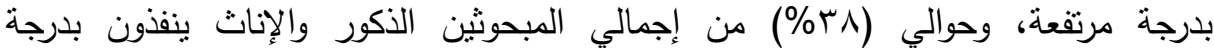

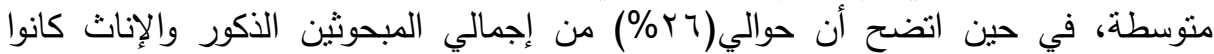

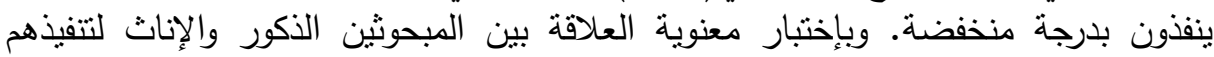

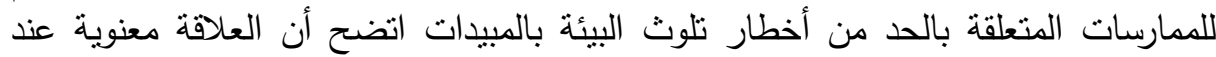

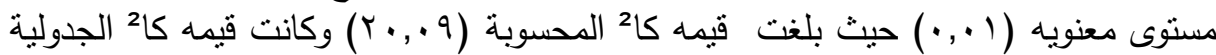

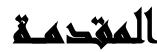

لم يعد مفهوم التتمية قاصراً على تحقيق التقدم الاقتصادي والاجتماعي فحسب بل

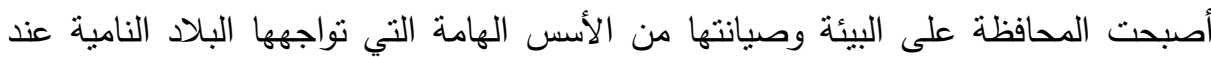
التخطيط للتمية، ولم تعد اعنبارات التتمية عذراً لتجاهل المحافظة على البيئة واتخاذ التدابير

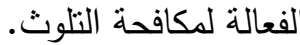

ولذا أصبح تلوث البيئة في مقدمة الموضوعات التي تحظي بالاهنمام وتثير المناقثنات في مختلف الأوساط والدوائر العامة والخاصة نظراً لخطورته على الصحة والاقتصاد وعلاقته بكافة لهات

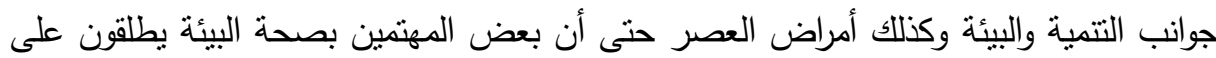
هذا العصر اسم "عصر التلوث" نظرا لانتشار ظاهرة التلوث وتعدد آثارها في كل مكان لما نعانيه

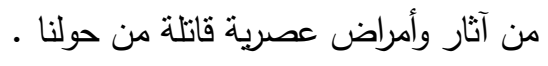


ويعتبر التلوث بالمبيدات من أنواع التلوث العديدة حيث صنفت بأنها ضارة على صحة الإنسان والحيوان والطيور والنبات، وأثنياء أخرى غير حية، وقد أدى الإسراف في استخدامها

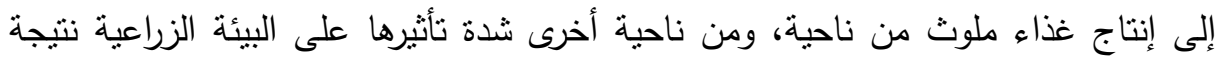

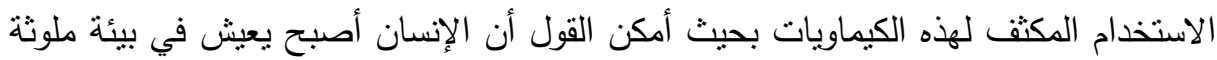
وغير نظيفة.

وبصفة عامة ينسم الريف المصري بالاستخدام المكثف للمبيدات الزراعية كوسيلة أساسية

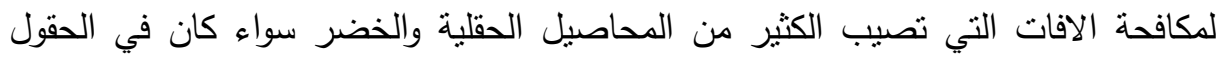
المفتوحة أو الزراعات المحمية، ويدل الواقع الفعلي أن غالبية المستخدمين لهذه المبيدات من لهن

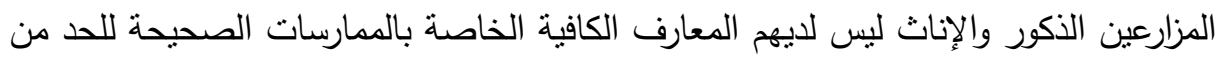
أخطار التلوث البيئي بالمبيدات، وعادة ما يشترك أغلب أو بعض أفراد الاسرة الريفية من

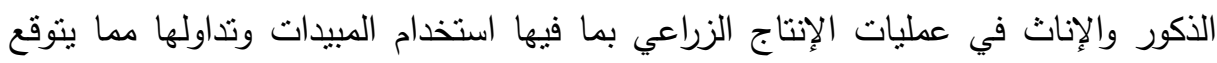
حدوث ممارسات خاطئه يترتب عليها حدوث تلوث بيئي ناتج من استخدام هذه المبيدات.

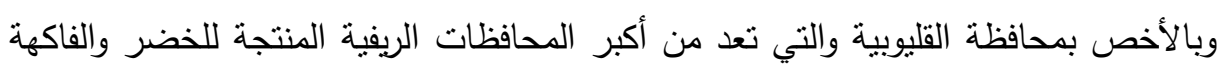
والمحاصيل الحقلية ولذا يقوم مزارعيها من الذكور والإناث بإستخدام أكبر قدر من المبيدات الزراعية. ولمواجهة هذا الموقف المتردي تسعى الدولة إلى اتخاذ العديد من الإجراءات والسياسات

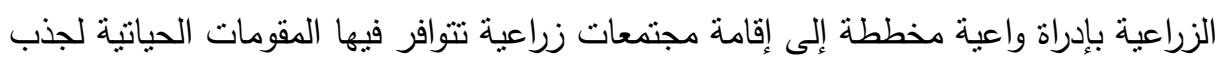

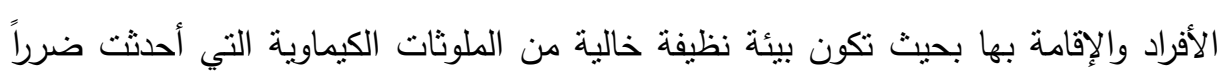

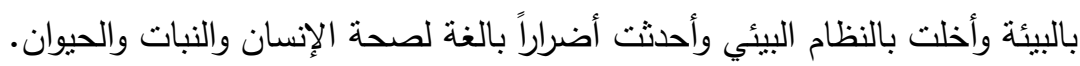

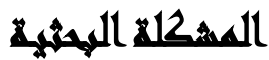

تفاقت في السنوات الأخيرة بجمهورية مصر العربية مشاكل التلوث البيئي عموماً وبالمبيدات الزراعية بشكل حاد وزاد الاهتمام بمحاولة ايجاد السبل الكفيلة بوقف وتخفيف حدة بهن هذا التلوث الذي نتج عن الإسراف في استخدامها رغم كل القيود والمحاذير التي تمنع ذلك.

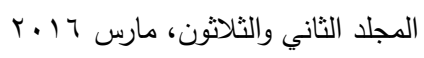


ورغم ذلك تتعرض البيئة الزراعية المصرية في الوقت الحالي للاستخدام غير الرشيد

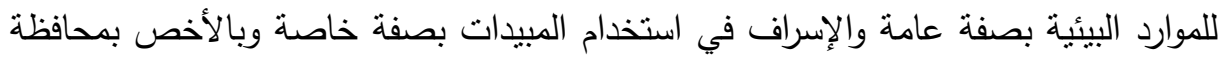
القليوبية والتي تعد من أكبر المحافظات الريفية المنتجة للخضر والفاكهة والمحاصيل الحقلية، ولذا يقوم مزارعيها بإستخدام أكبر قدر من المبيدات الزراعية وقد يرجع ذلك لوجود أنماط

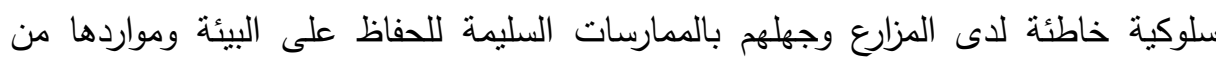

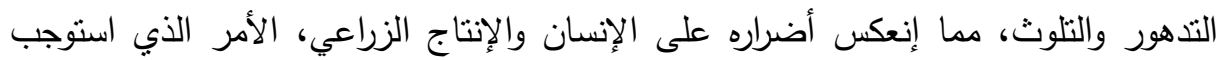

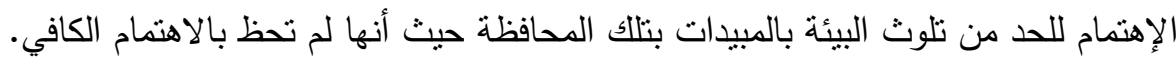
ويمكن القول بأن هنالك فجوة في معارف الزراع بالممارسات الصحيحة في هذه المحافظة

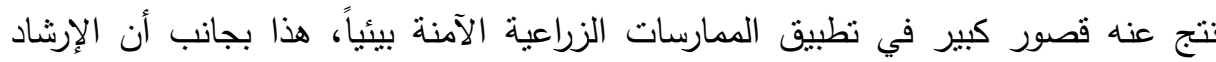

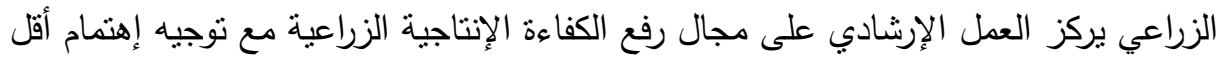

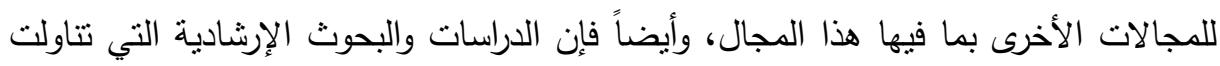

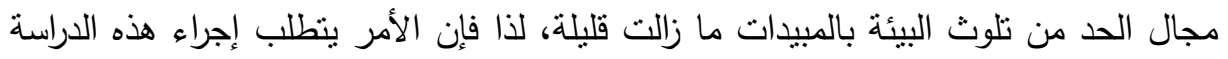

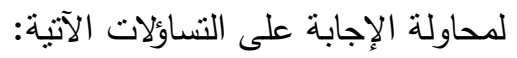
())ما هو مستوى معارف المبحوثين (الذكور والإناث) بالتوصيات الفنية المتعلقة بالحد من الإنهات تلوث البيئة بالمبيدات في منطقة الدراسة. r) ما هو مستوى تتفيذ المبحوثين (الذكور والإناث) للممارسات المتعلقة بالحد من تلوث البيئة بالمبيدات في منطقة الدراسة. ץ) ماهي الفروق بين المزارعين المبحوثين من الذكور والاناث فيما يتعلق بكل بمعارفهم بالتوصيات الفنية ودرجة ممارستهم لها.

\section{أهبا اهن المهنه}

( ) التعرف على مستوى معارف المبحوثين(الذكور والإناث) بالتوصيات الفنية المتعلقة بالحد من أخطار تلوث البيئة بالمبيدات في منطقة الدراسة. 
r) التعرف على مستوى تتفيذ المبحوثين(الذكور والإناث) للممارسات المتعلقة بالحد من أخطار تلوث البيئة بالمبيدات بمنطقة الدراسة.

r) تحديد الفروق بين المزارعين المبحوثين(الذكور والاناث) فيما يتعلق بكل من مستوى باتئه

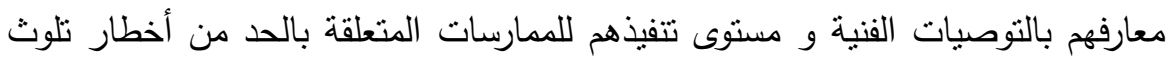
البيئة بالمبيدات بمنطقة الدراسة.

\section{أهمبد الهبه}

لا شك أن التعرف على مستوى معارف كلا من الذكور والإناث بالممارسات التي تحد من أخطار تلوث البيئة بالمبيدات في منطقة البحث بمحافظة القليوبيـة من شـأنه أن يفيد

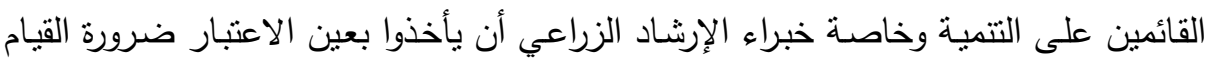

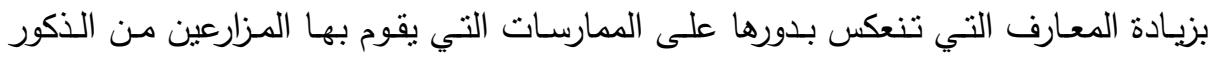

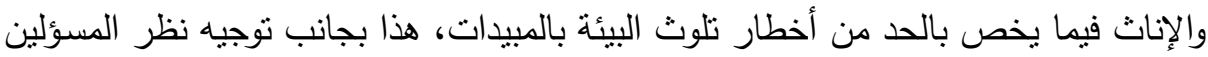

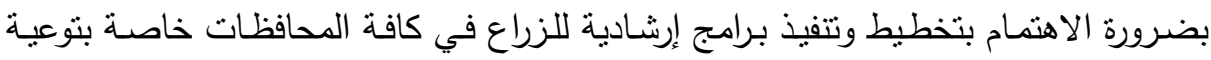
الزراع بالمعارف والممارسات الصحيحة في مجال الحد من تلوث البيئة بالمبيدات.

\section{الطريمنة المبحثية}

1) منطقة الاراسة: أُجريت هذه الدراسة في محافظة القليوبية نظراً لكونها إحدى المحافظات الرئيسية المنتجة للخضر والفاكهة والمحاصيل الحقلية- وما يترثب على ذلك

$$
\text { من استخدام مزارعيها لأكبر قدر من المبيدات الزراعية. }
$$

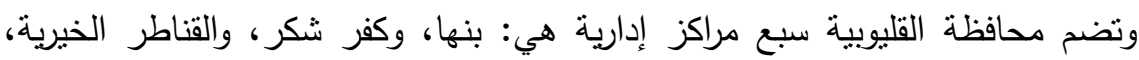
وطوخ، وقليوب، وشبين القناطر ، والخانكة.

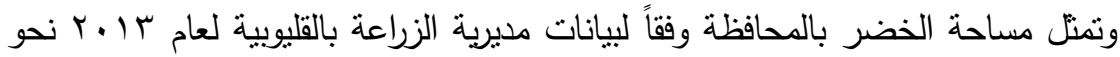

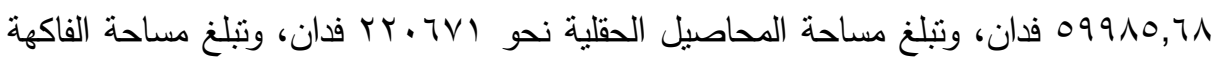

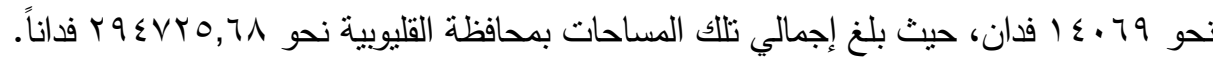

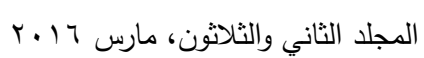


وبتطبيق معيار المساحة المنزرعة بمحاصيل الخضر والفاكهة والمحاصيل الحقلية على

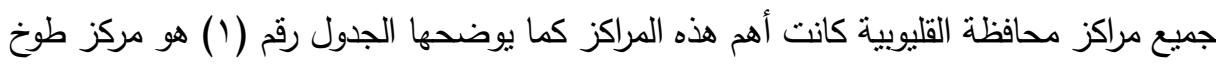

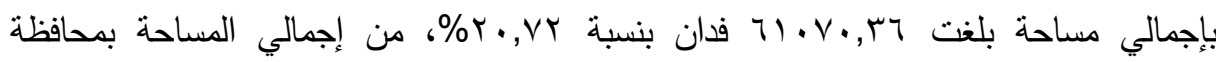
القليوبية. جدول رقم(1) (1) بيان بالمساحات المنزرعة من الخضر والمحاصيل الحقلية والفاكهة بالمراكز الإدارية لمحافظة القليوبية

\begin{tabular}{|c|c|c|c|c|c|c|}
\hline \multirow[b]{2}{*}{ الترتيب } & \multirow{2}{*}{$\begin{array}{c}\% \\
\text { للمساحة }\end{array}$} & \multirow{2}{*}{ إجمالي } & \multicolumn{3}{|c|}{ المساحة المنزرعة (فدان) } & \multirow[b]{2}{*}{ 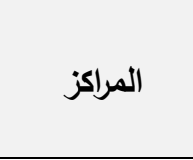 } \\
\hline & & & قاكهة & محاصيل & خضر & \\
\hline r & $1 \wedge, \Sigma \wedge$ & $0 \leqslant \leqslant V V, 1\}$ & $\varepsilon \leqslant r$ & $\varepsilon \vee \leqslant \Lambda$. & 7000,17 & بنها \\
\hline V & $r, V T$ & $\wedge 11 \cdot, 1 \wedge$ & r & VTor & 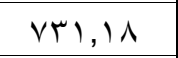 & كفر شكر \\
\hline 0 & $1 T, \cdot T$ & 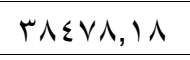 & Mr,IA & TVV.. & 1.507 & القتاطر الخيرية \\
\hline 1 & $Y \cdot, V Y$ & $7) \cdot V \cdot r$ & I ITr,Yr & $\varepsilon \leqslant 9 \vee 1$ & $1 \leq 177,1 \leq$ & طوخ \\
\hline$r$ & $11,0 Y$ & $0 \leqslant 090, \leqslant Y$ & $1900, Y Y$ & MIIו & $17 \leqslant r q, r$ & قليوب \\
\hline$\varepsilon$ & IV,IT & $0 . \leq \wedge 9,1 \wedge$ & orrA, IN & $\varepsilon \cdot V \cdot O$ & $\leq 0 \leq 7$ & شبين القتاطر \\
\hline 7 & q, & rIV0.0,r & $\varepsilon 100, r$ & ITY $\leq 1$ & $V I \cdot r$ & الخانكة \\
\hline- & $1 \ldots$ & $r q \leq \vee r 0, T \wedge$ & 15.79 & Yr.TVI & 09910,71 & الإجمالي \\
\hline
\end{tabular}

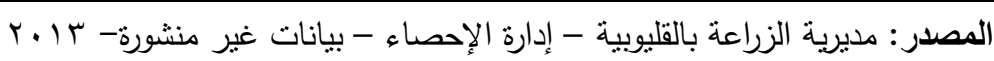

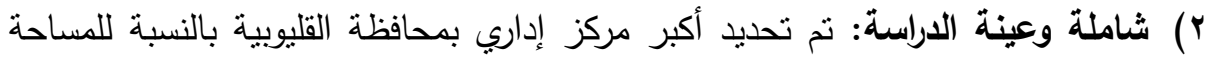

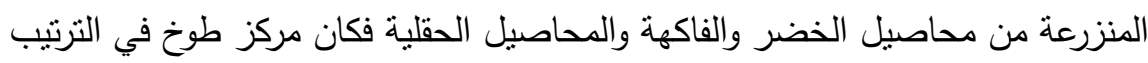

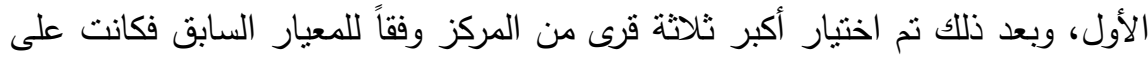

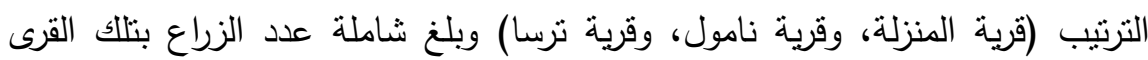

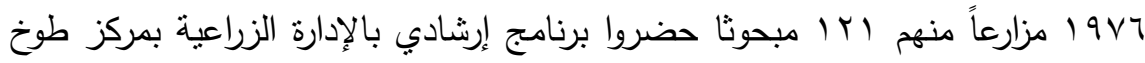

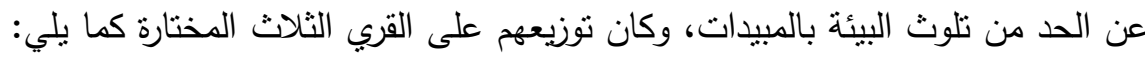

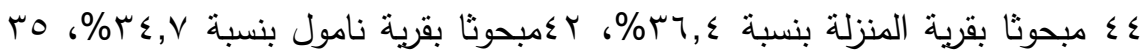

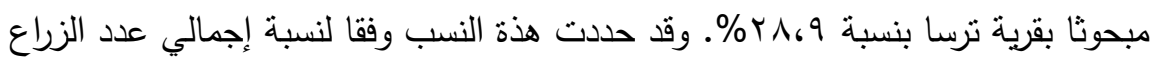


بكل قرية منسوبة إلى إجمالي عدد الزراع في القرى الثثلاث المختارة، كما في الجدول

جدول رقم(Y): نوزيع المبحوثين أفراد المجموعة التجريبية بالقرى المختارة للاراسة

\begin{tabular}{|c|c|c|c|c|c|c|c|}
\hline \% للعينة & لمستخذمة & \% الزارع عدد & عداد & (فدان) & المخترية & مساحة المركز & لمركز \\
\hline r & $\varepsilon \varepsilon$ & $\mu^{\prime}, \cdot$ & VIr & $r \mid r, r$ & المنزلة & \multirow{3}{*}{ צ } & \multirow{3}{*}{ طوخ } \\
\hline$r \varepsilon, v$ & $\varepsilon r$ & $r \Delta, \Lambda$ & 794 & $411 \leqslant, 7$ & نامول & & \\
\hline$r \wedge, q$ & o & $r \wedge, q$ & ovi & $Y r \leq \neg, \varepsilon$ & ترسا & & \\
\hline $1 \cdots$, & $|r|$ & $1 \ldots$, & 1987 & & & الإجمالي & \\
\hline
\end{tabular}

المصدر: جمعت وحسبت من بيانات مديرية الزراعة بالقليوبية إدارة الإحصاء- بيانات غير منشورة -

r. 14

r- تجميع بيانات الدراسة: اعتمد في جمع بيانات الدراسة على المقابلة الثخصية للباحثة

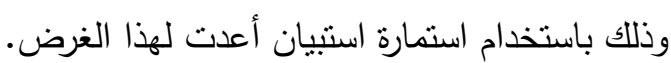

وقد تضمنت استمارة الاستبيان ثلاثة أجزاء تتاول الجزء الأول منها أسئلة تعكس الخصائص الثخصية والاجتماعية للمزارعين المبحوثين وهي (السن، والجنس، والمسنوى التعليمي، والمهنة، وحجم الحيازة الزراعية، وعدد سنوات الخبرة في العمل الزراعي، والمشاركة المجتمعية، والتعرض لمصادر المعلومات الزراعية، والاتجاه نحو الإرشاد الزراعي)، والجزء الثاني اختص بمستوى معارف المبحوثين بالتوصيات الفنية المتعلقة بالحد من أخطار تلوث الزئه البيئة بالمبيدات، والجزء الثالث اهتم مستوى معارفهم بمفاهيم تلوث البيئة وطرق وصول المبيد

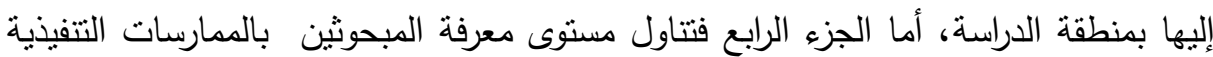
المتعلقة بالحد من أخطار تلوث البيئة بالمبيدات. هذا وبعد الانتهاء من تصميم استمارة الاستبيان تم عرضها على مجموعة من المحكمين، ونم إجراء الاختبار المبئي لها Pre-test خلال شهر ديسمبر rا بr للتعرف على صلاحية أسئلة استمارة الاستبيان من حيث الدقة والفهم من وجهة نظر المبحوثين لتحقيق أهداف الدراسة، وذلك على خمسة عشر مزارع بقرية شبلنجة بمركز بنها وقد تم إجراء 
التعديلات اللازمة في تصميم استمارة الاستبيان وذلك بناءاً على نتائج الاختبار المبدئي وآراء المحكمين في المادة الفنية للبرنامج.

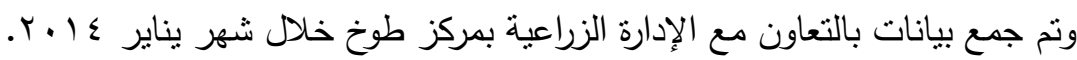
ع - معالجة البيانات: لكي تحقق البيانات التي جمعت أهداف البحث تم تفريغها وتبوييها وجدولتها، وتم استخدام أساليب التحويل الرقمي للإجابات على أسئلة الاستمارة بما يجعلها

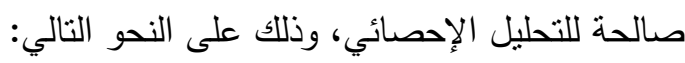
أ- قياس معرفة المبحوثين بالتوصيات الفنية المتعلقة بالحد من مخاطر تلوث البيئة بالمبيدات بمنطقة الدراسة: تم القياس عن طريق إعطاء كل مبحوث درجة واحدة في حالة معرفته بالبنود المدروسة وعددها إحدى وعثرون عبارة، وبذلك تكون أعلى درجة للمعرفة

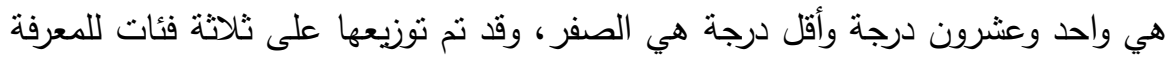

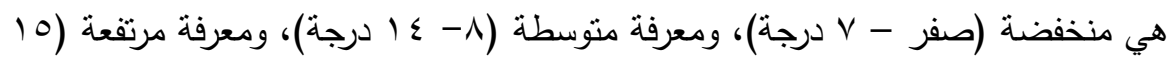

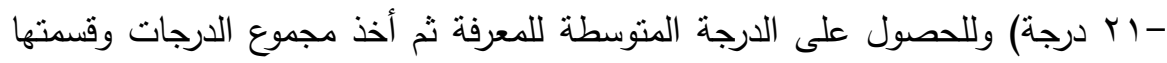
على عدد التوصبات الفنية وبذلك أمكن الحصول على درجة تعبر عن منوسط درجات المعرفة، وقد نم توزيع المبحوثين وفقا للمتوسط الحسابي لدرجة معارفهم إلى ثلاث فئات

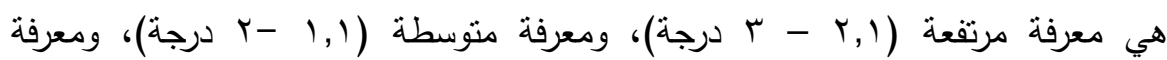
منخفضة (صفر - درجة). وتم حساب المتوسط الكلي لدرجة معرفة المبحوثين بضرب درجة كل فئة في عدد التكرارات الخاصة بها ثم جمع وقسمة المجموع على عدد المبحوثين ب- قياس تنفيذ المبحوثين للتوصيات الفتية المتعلقة بالحد من مخاطر تلوث البيئة بالمبيدات بمنطقة الاراسة: تم القياس عن طريق إعطاء كل مبحوث درجة واحدة في حالة إجابته الصحيحة

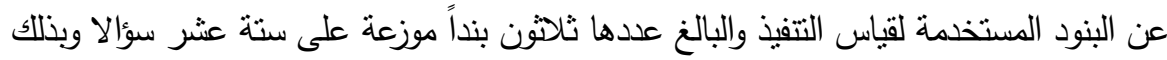
تكون أكبر درجة للتنفيذ هي ثلاثون درجة وأقل درجة هي الصفر ، وقد تم نوزيعها على ثلاثة

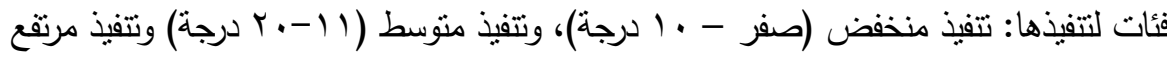

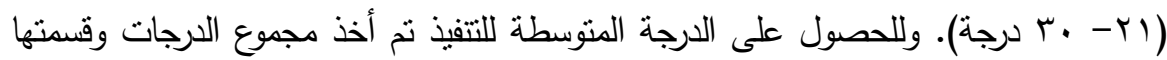
على عدد البنود المستخدة لقياس التنفيذ وبنلك أمكن الحصول على درجة تعبر عن منوسط

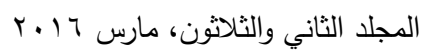


درجات التنفيذ، وقد نم توزيع المبحوثين وفقاً للمتوسط الحسابي لدرجة تنفيذهم إلى ثلاث فئات

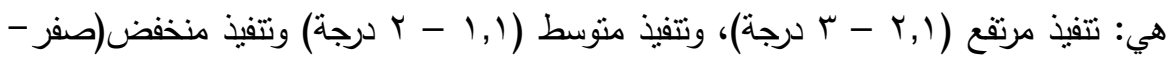
درجة). وتم حساب المتوسط الكلي لدرجة تتفيذ المبحوثين بضرب درجة كل كل فئة في عدد التكرارات الخاصة بها ثم جمعتها وقسمة المجموع على عدد المبحوثين. ج-قياس معرفة المبحوثين بالتوصيات المتعلقة بمفاهيم تلوث البيئة وطرق وصول المبيا إليها: تم القياس عن طريق إعطاء كل مبحوث درجة واحدة في حالة معرفته بالبنود المدروسة وعددها

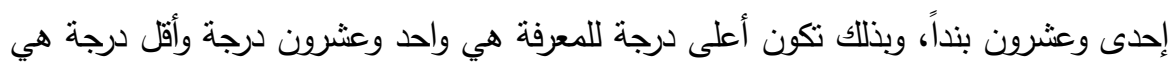

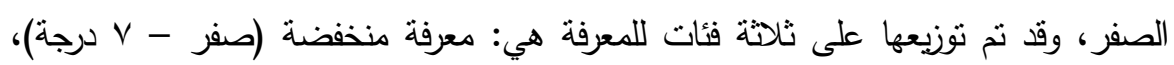

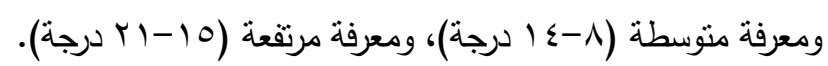

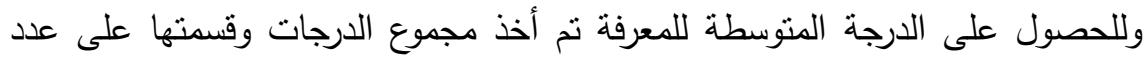
البنود المستخدمة لقياس المعرفة وبذلك أمكن الحصول على درجة تعبر عن منوسط درجات

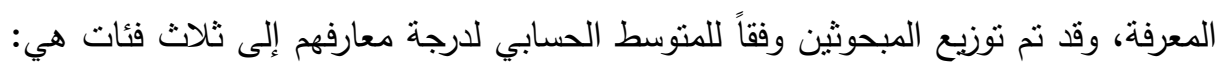

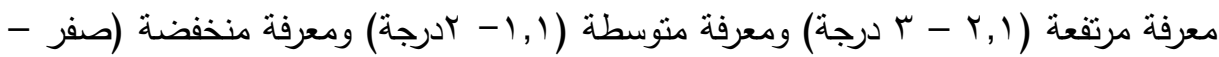

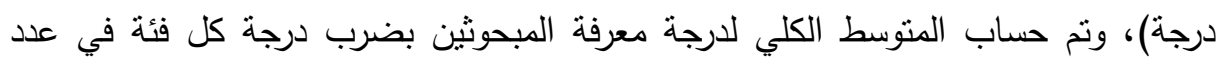
التكرارات الخاصة بها ثم جمعها وقسمة المجموع على عدد المبحوثين. 
ه- أدوات التحليل الإحصائي: لتحليل بيانات الدراسة إحصائياً استخدم في عرض البيانات

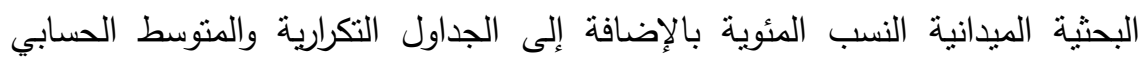
معامل التطابق النسبي كا، وذلك باستخدام البرنامج الإحصائي (SPSS).

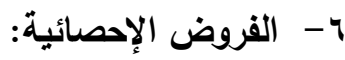
1-توجد فروق دالة إحصائيا في درجة معرفة المزارعين المبحوثين (الذكور والاناث) فيما يتعلق بالتوصيات الفنية المتعلقة بالحد من تلوث البيئة بالمبيدات.

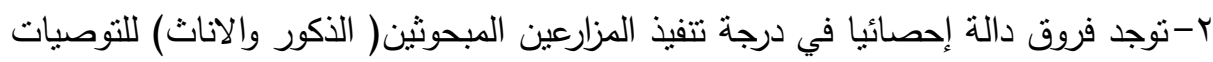
الفنية المتعلقة بالحد من تلوث البيئة بالمبيدات.

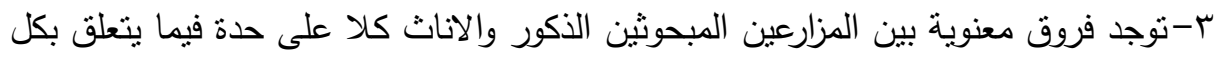

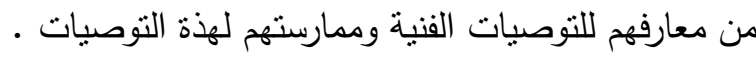
ولاختبار هذة الفروض تم وضعها في صورتها الصفرية بوضع كلمة "لا" أمام كل فرض بحثي.

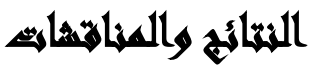

أولا : وصف الخصائص الثخصية والإجتماعية للمزارعين المبحوثين من الذكور والإناث.

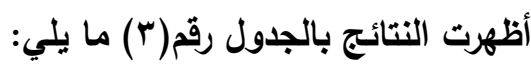

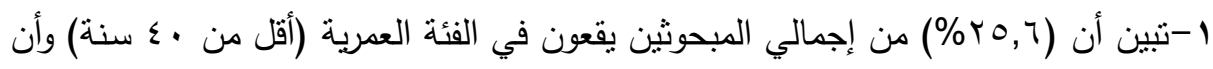

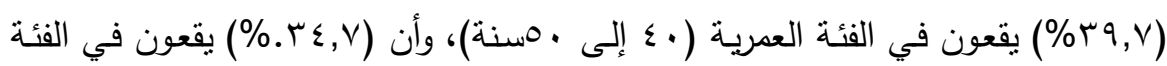
العمرية (ا0 سنة فأكثر).

ومن هذه النتائج إتضح أن الفئة العمرية الأكثر اشتراكا كان أغلب الأفراد بها لديهم

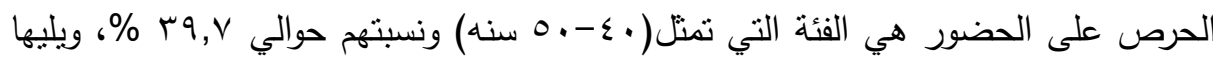

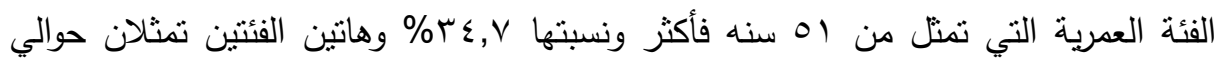

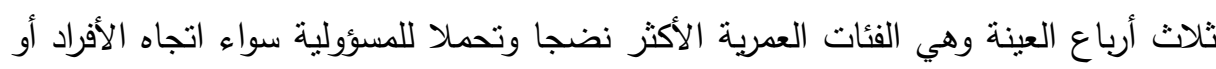
أنفسهم أو البيئة وهي في الأغلب الفئات التي قضت أكثر وقت التئ من عمرها في في العمليات

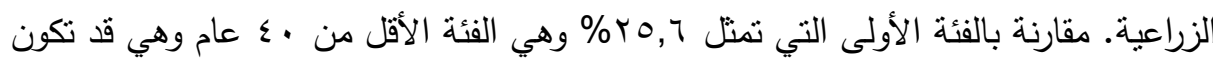

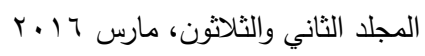


الأجيال الجديدة التي حرصت أسرهم على تعليمهم والابتعاد عن مجال الزراعة والإنشغال بالمشاريع الصغيرة، وهذا واقع أصبح ملموسا في المجتمع الريفي المصري.

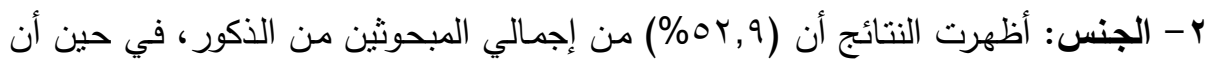
\% \& , ,

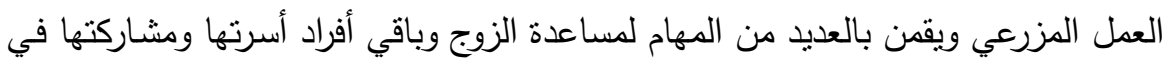
الأعمال المزرعية لتحسين دخل الأسرة، وبالطبع فإن نسبة الذكور أعلى من نسبة الإناث

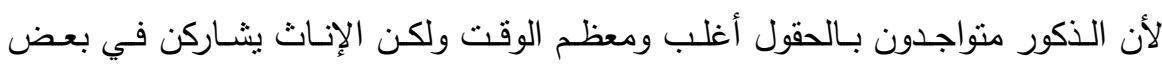
الأوقات نظرا لانشغالها بالمنزل ولكنها تشارك في العمل المزرعي.

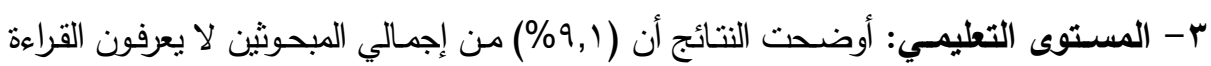

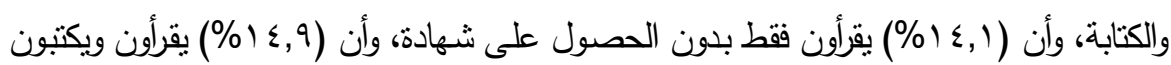

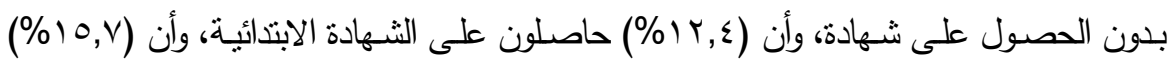

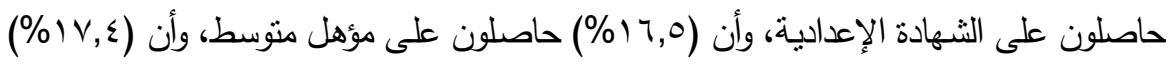
حاصلون على مؤهل جامعي فأعلى.وهذه النسب تدل على تفاوت مستوى التعليم بين المبحوثين وريما يدل هذا على تفاوت الإدراك واستيعاب المعلومات بين فئات المبحوثين المختلفة.

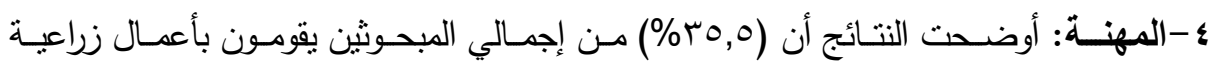

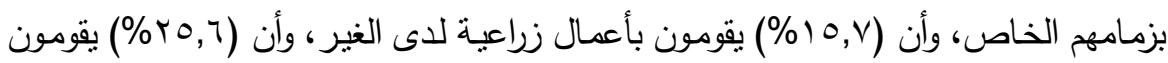

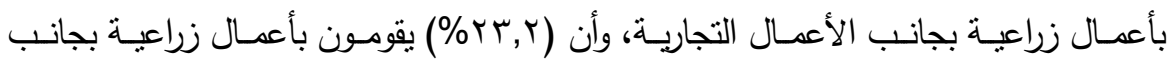

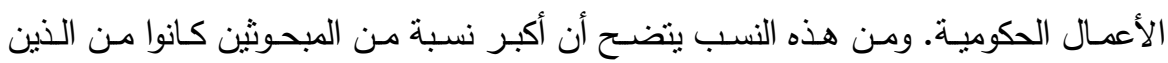

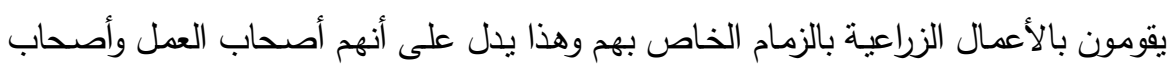

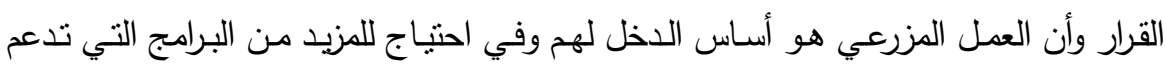
السلوك نحو الحد من نلوث البيئة بالمبيدات بخلاف الفئات الأخرى سواء كانوا يعملون لدى

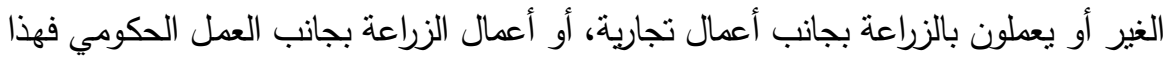

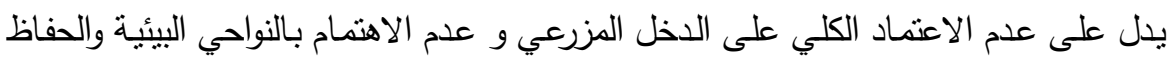

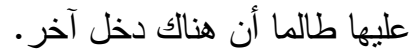


ه-حجم الحيازة الزراعيـة: تعتبر الحيازة عنصرا أساسيا في النظام الاجتماعي، بإعتبار أن

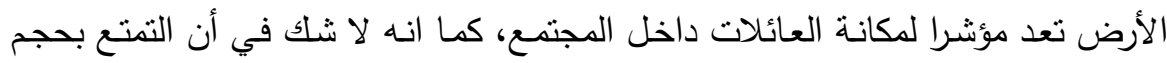
حيازة مزرعية كبيرة يزيد سهولة استيعاب الأفكار المستحدثة ومن ثم القدرة على التغيير

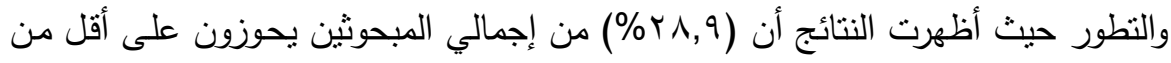

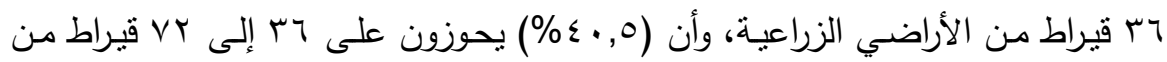

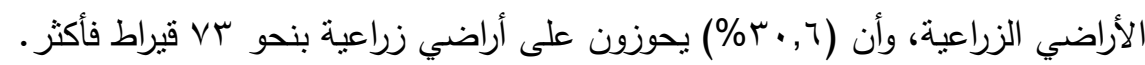

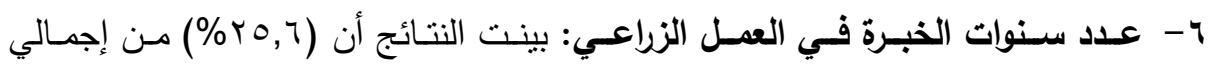

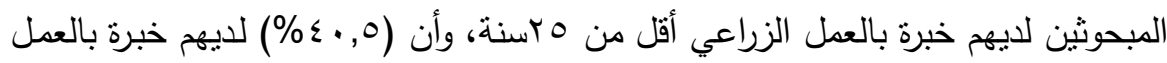

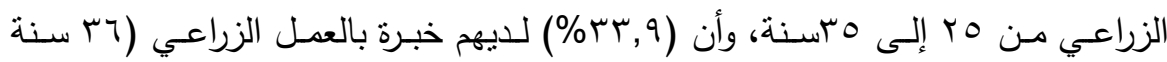

ومن هذه النسب يتضـح طول الفترة التي قضـاها المبحوثين في العمل المزرعي مهـا يعطيه خبرة أكثر فيه.

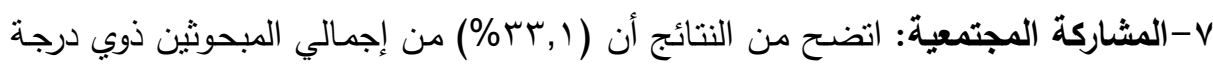

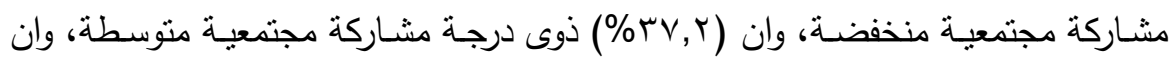

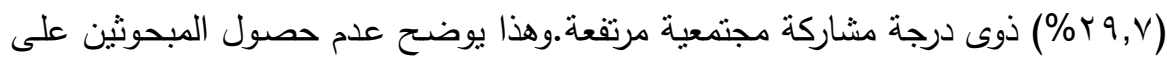

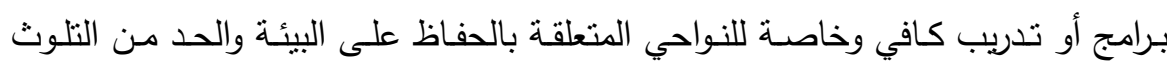
بالمبيدات. أو عدم توفر البرامج التي يكون المبحوثين في حاجة إليها.

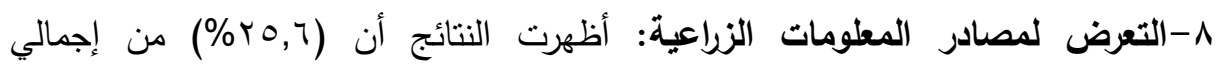

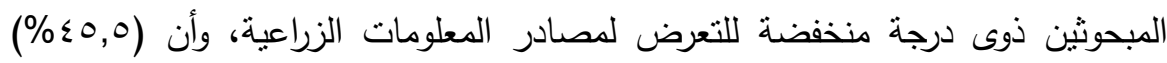

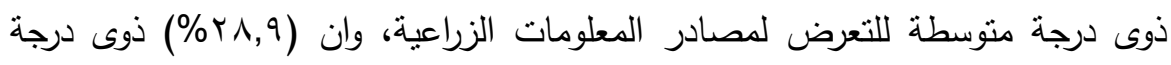

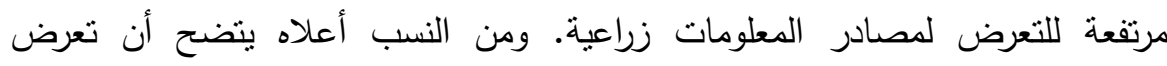
المبحوثين لمصادر المعلومات كانت النسبة الأكبر منهم والتي تمثل 0,0 ؛ ٪ نقع في الفئة

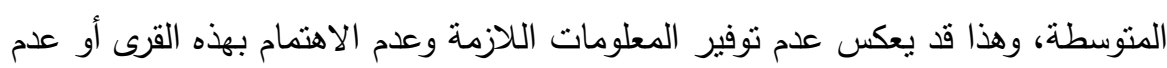


حرص المبحوثين أنفسهم على تلقي المعلومات واعتمادهم على الخبرات الثخصية أو

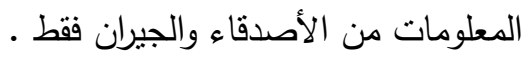

9- الاتجاه نحو الإرشاد الزراعي: أوضحت النتائج أن (ع ,جr\%) من إجمالي المبحوثين

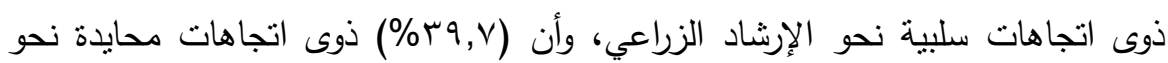

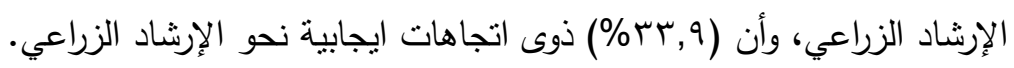

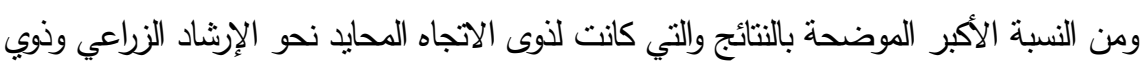

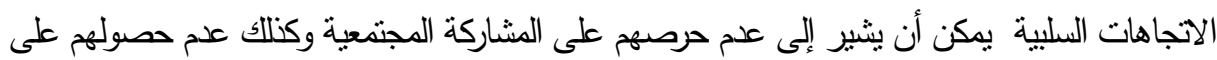
المعلومات التي بلورها تؤئز على معارفهم وعدم اهتمامهم بالنواحي الإرشادية.

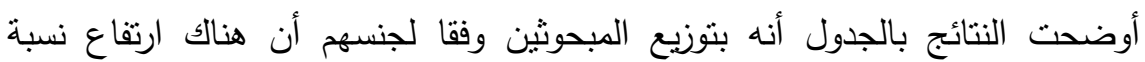

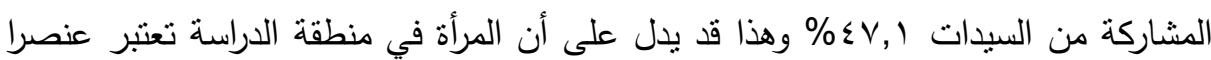

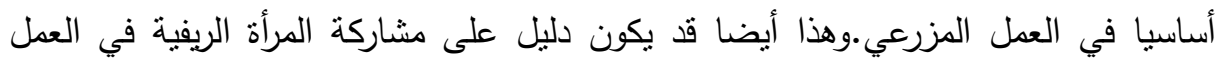

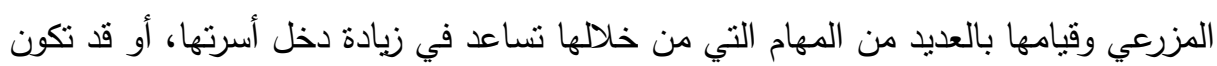
بغرض مساعدة الزوج لتوفير تكاليف العمال. 
مجلة العلوم البيئية

معهد الدراسات والبحوث البيئية - جامعة عين شمس لئ

جدول رقم(ץ) : نوزيع المبحوثين وفقا لخصائصهم الثخصية

\begin{tabular}{|c|c|c|c|c|}
\hline$\%$ & 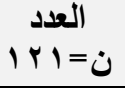 & الفئات & الخصائص المدروسة & م \\
\hline$r_{0,7}$ & Tा & (أقل من • •ـ سنة) & \multirow{3}{*}{ 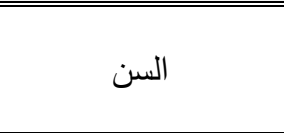 } & \multirow{3}{*}{1} \\
\hline$r 9, v$ & $\varepsilon \wedge$ & ( (·ء إلى •0 سنة) & & \\
\hline$r \varepsilon, v$ & $\sum r$ & (1 ( سنة فأكثر) & & \\
\hline or, 9 & $7 \varepsilon$ & ذكر & \multirow{2}{*}{ 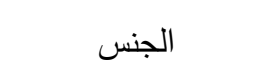 } & \multirow{2}{*}{ r } \\
\hline$\varepsilon \vee, 1$ & ov & أنثى & & \\
\hline 9,1 & 11 & لا يعرف القراءة والكتابة & \multirow{7}{*}{ المستوى التعليمي } & \multirow{7}{*}{ r } \\
\hline $1 \leqslant,$. & iv & يقرأ فقط بدون الحصول على شهادة & & \\
\hline $1 \leqslant, 9$ & 11 & يقرأ ويكتب بدون الحصول على شهادة & & \\
\hline IY, \{ & 10 & حاصل على الثهادة الابتدائية & & \\
\hline $10, \mathrm{~V}$ & 19 & حاصل علي الثهادة الإعدادية & & \\
\hline 17,0 & r. & حاصل على الثهادة الثانوية & & \\
\hline$I V, \varepsilon$ & r) & حاصل على مؤهل جامعى فأَعلى & & \\
\hline$r 0,0$ & $\varepsilon r$ & أعمال زراعية بالزمام الخاص & \multirow{4}{*}{ 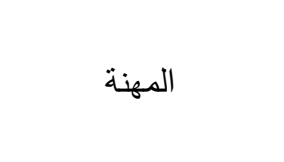 } & \multirow{4}{*}{$\varepsilon$} \\
\hline $10, \mathrm{~V}$ & 19 & أعمال زراعية لدى الغير & & \\
\hline ro, 7 & r) & أعمال زراعية بجانب الأعمال التجارية & & \\
\hline$r r, r$ & rA & أعمال زراعية بجانب الأعمال الحكومية & & \\
\hline$r \Lambda, q$ & ro & منخفضة (أقل من جr قيراط) & \multirow{3}{*}{ حجم الحيازة الزراعية } & \multirow{3}{*}{ o } \\
\hline$\varepsilon \cdot, 0$ & $\leqslant 9$ & متوسطة (كَrإلى VY Vيراط) & & \\
\hline$r \cdot, \tau$ & rv & كبيرة (rّ قبراط فأكثر) & & \\
\hline$r_{0,7}$ & r) & منخفضة (أقل من Yo سنة) & \multirow{3}{*}{ عدد العنوات الخبرة في } & \multirow{3}{*}{1} \\
\hline$\varepsilon \cdot, 0$ & $\sum 9$ & متوسطة ( (1) إلى 0ب سنة) & & \\
\hline$r r, q$ & $\varepsilon 1$ & مرتفعة (T سنة فأكثر) & & \\
\hline$r+1$ & $\varepsilon$. & منخفضة (أقل من ؟ درجات) & \multirow{3}{*}{ المشاركة المجتمعية } & \multirow{3}{*}{$\mathrm{v}$} \\
\hline$r v, r$ & $\leq 0$ & متوسطة (ع إلى 7 درجات) & & \\
\hline$r 9, \mathrm{~V}$ & r4 & مرتفعة (V درجات فأكثر) & & \\
\hline$r 0,7$ & TI & منخفض (أقل من V درجات) & \multirow{3}{*}{ المعلومات الزراعية } & \multirow{3}{*}{$\wedge$} \\
\hline$\{0,0$ & 00 & منوسطة (V إلى ؟ Y Y درجة) & & \\
\hline$r \wedge, q$ & ro & مرتفع (بَ ا درجة فأكثر) & & \\
\hline YY, \& & rY & سلبي (أقل من ^ درجات) & \multirow{2}{*}{ الاتجاه نحو الإرشاد } & \multirow{3}{*}{9} \\
\hline $\begin{array}{l}r q, v \\
r r q\end{array}$ & $\begin{array}{l}\varepsilon \wedge \\
\varepsilon 1\end{array}$ & محايد (1 إلى عة ( أرجثة) & & \\
\hline & & إيجابي ( ها لرجه مسر) & & \\
\hline
\end{tabular}


ثانيا: مستوى معارف المبحوثين(الذكور والإناث) فيما يتعلق بالتوصيات الفنية المتعلقة بالحد من أخطار تلوث البيئة بالمبيدات في منطقة الدراسئة:

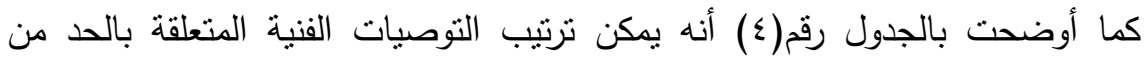

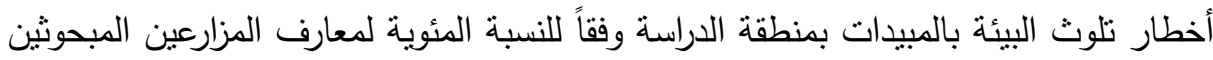

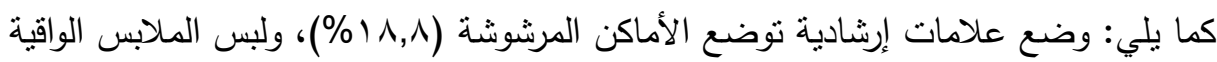

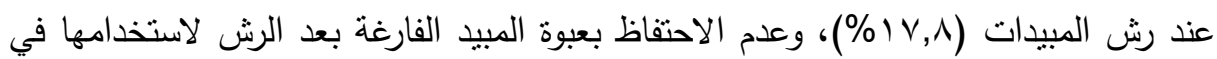

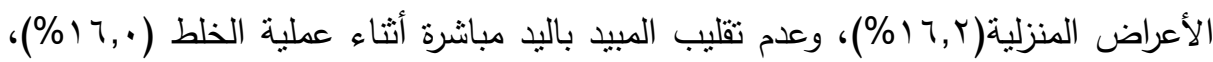

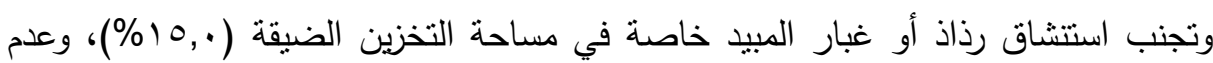

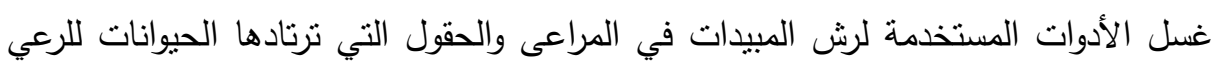

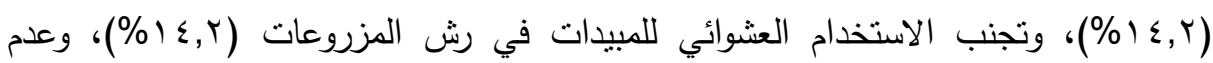

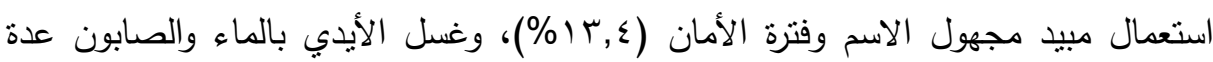

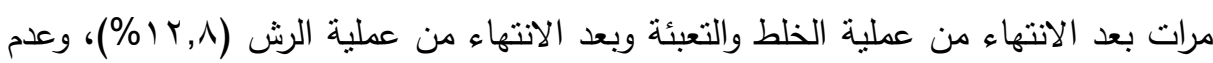

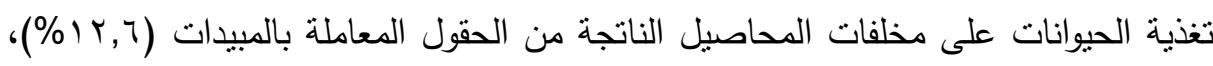

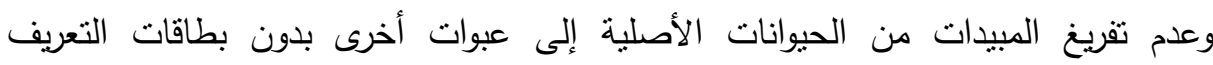

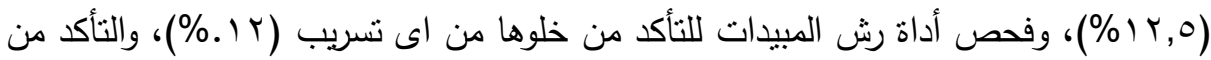

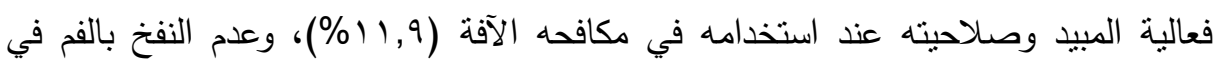

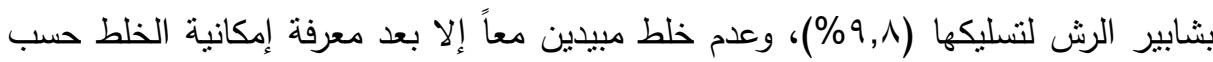

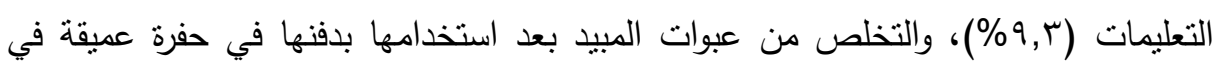

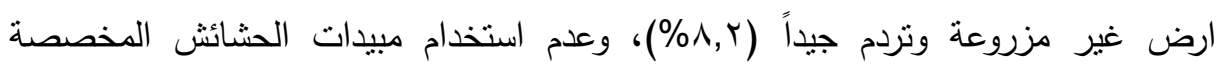

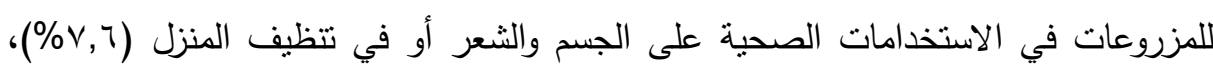
وحفظ المبيد في مكان مظلل وجاف وذو تهوية جيدة (؟, ؟\%)، وعدم الاحتفاظ بعبوة المبيد

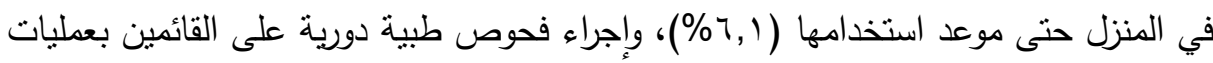
الرش المبيدات ( •,0\%)، وأخيراً استعمال رشاشة ذات قصبة طويلة لرش الأشجار أو استخدام

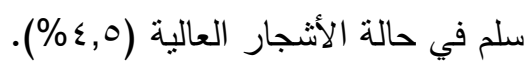


جدول رقم(؛ ): توزيع المبحوثين الذكور والإناث وفقاً لمعرفتهم بالتوصيات الفنية المتعلقة بالحد

من أخطار تلوث البيئة بالمبيدات بمنطقة الدراسة.

\begin{tabular}{|c|c|c|c|}
\hline $\begin{array}{c}\% \\
|r|=\dot{0}\end{array}$ & عدد & 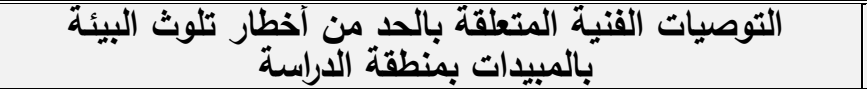 & p \\
\hline Ar, & $1 \ldots$ & حفظ الميبد في مكان مظلل وجاف وذو تهوية جيدة & 1 \\
\hline $9 \wedge, r$ & 119 & الأغراض الاحتفاظلية بعبوة المبيد الفارغة بعد الرش لاستخدامها في & r \\
\hline $\mathrm{V}, \mathrm{l}$ & $\Lambda 7$ & عدم استعمال مبيد مجهول الاسم وفترة الآمان & r \\
\hline $\mathrm{V} 0, \mathrm{r}$ & 9) & عدم الاحتفاظ بعبوة المبيد في المنزل لفترة حتى موعد استخدامها & $\varepsilon$ \\
\hline $7 \vee, \Lambda$ & Ar & التعليمات خلط مبيدين معاً إلا بعد معرفة إمكانية الخلط حسب & 0 \\
\hline$\Lambda T, 0$ & $1 \cdot 1$ & عدم تقلبب المبيد بالبد مباشرة أثناء عملية الخلط & 7 \\
\hline $91, \mathrm{~V}$ & 111 & لبس الملابس الواقية عند رش المبيدات & $\mathrm{V}$ \\
\hline or, 9 & $7 \varepsilon$ & عدم النفخ بالفم في بشابير الرش لتنسليكها & $\Lambda$ \\
\hline$V\urcorner, \cdot$ & 94 & في حالة الأشتارة ذات قالية قصبة طويلة لرش الآثجار أو استخدام سلم & 9 \\
\hline$V \varepsilon, \varepsilon$ & 9 . & والحقول غسل التى ترتدها الحيوانات المستخدمة للرشى المبيدات في المراعى & 1 . \\
\hline$\Lambda \varepsilon, \Gamma$ & $1 \cdot Y$ & 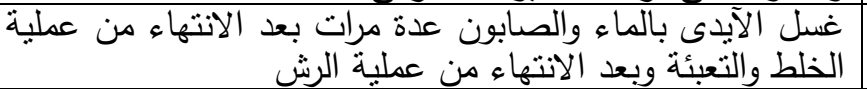 & 11 \\
\hline 71,9 & Vo & في أرضل غن عزورات المبيد بعد استخدامها بدفنها في حفرة عميقة & Tr \\
\hline $7 \cdot, r$ & VT & وضع علامات إرشادية توضح الأماكن المرشوشة & IT \\
\hline$\Lambda \cdot, r$ & $9 \mathrm{~V}$ & التأكد من فعالية المبيد وصلاحية عند استخدامه في مكافحة الآفة & $1 \varepsilon$ \\
\hline$V \cdot, r$ & 1. & 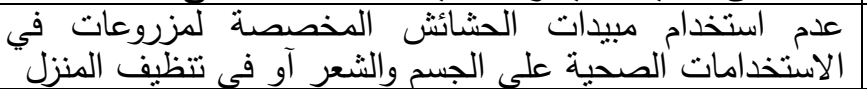 & 10 \\
\hline$\vee q, r$ & 97 & المعاملة بذالمبيدات الحيوانات على مخلفات المحاصيل الناتجة من الحقول & 17 \\
\hline $0 \wedge, \mathrm{V}$ & v) & أجراء فحوص طبية دورية على القائمين بعمليات رش المبيدات & IV \\
\hline$V V, 9$ & $9 \leq$ & فحص أداة رش المبيدات للتأكد من خلوها من أي تسريب & 11 \\
\hline$V 0, r$ & 91 & تلبنبة استتشاق رزاز أو غبار المبيد خاصة في مساحات التخزين & 19 \\
\hline 71,7 & N & بطاقات التنعريف المبيدات من العبوات الآصلية إلى عبوات أخرى بدون & r. \\
\hline $\mathrm{V}, \mathrm{q}$ & $\Lambda \mathrm{V}$ & تجنب الاستخدام العشوائي للمبيدات فى رش المزروعات & Y) \\
\hline$\vee \varepsilon, \Gamma \wedge$ & 9. & & \\
\hline
\end{tabular}


ويالنسبة لتحديد الفروق بين المبحوثين من الذكور والاناث وفقا لمستوى معارفهم بالتوصيات الفنية المتعلقة بالحد من أخطار تلوث البيئة بالمبيدات في منطقة الدراسة لئن

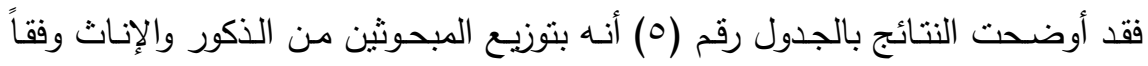

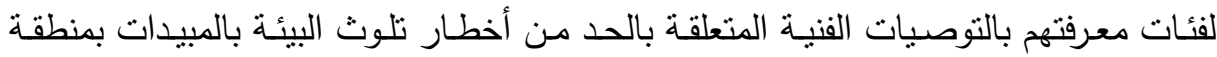

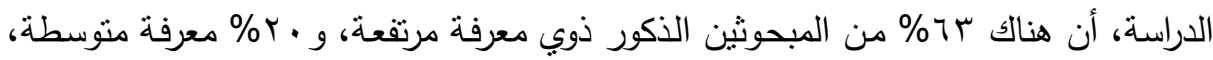
و V V V معرفة منخفضة، وهذا يشير أن هناك مستوى معرفي مرتفع للمبحوثين الذكور .

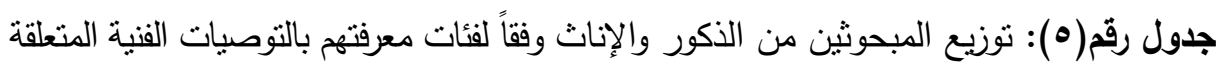
بالحد من أخطار تلوث البيئة بالمييدات بمنطقة الدراسة البانة

\begin{tabular}{|c|c|c|c|c|c|c|}
\hline \multicolumn{6}{|c|}{ توزيع المبحوثين } & \multirow{4}{*}{ فئات المعرفة } \\
\hline \multicolumn{6}{|c|}{ عدد } & \\
\hline \multicolumn{2}{|c|}{ إجمالى } & \multicolumn{2}{|c|}{ إناث } & \multicolumn{2}{|c|}{ ذكور } & \\
\hline$\%$ & عدد & $\%$ & عدد & $\%$ & عدد & \\
\hline Tr & TV & rᄉ & 17 & $1 \mathrm{~V}$ & 11 & معرفٌة منخفضة \\
\hline 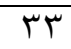 & $\varepsilon$. & $\varepsilon V$ & TV & $r \cdot$ & 14 & معرفة متوسطة \\
\hline$\leqslant 0$ & $0 \leqslant$ & ro & $1 \varepsilon$ & r & $\varepsilon$. & معرفة مرتفعة \\
\hline $1 \cdots$ & $\mid Y 1$ & $1 \cdots$ & OV & $1 \ldots$ & $7 \varepsilon$ & مجموع \\
\hline
\end{tabular}

المصدر: جمعت وحسبت البيانات من نتائج الاستبيان.

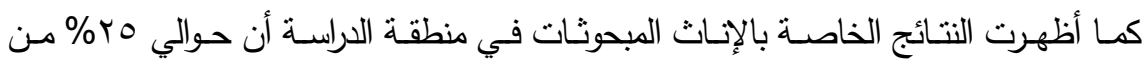

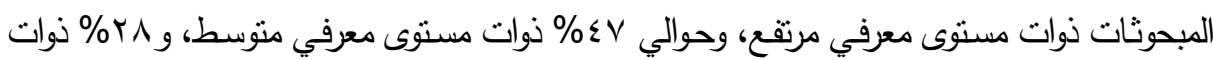
مستوى معرفي منخفض بالرغم أن أعلى النسب تمنلت في الفئة المعرفية المنوسطة للإناث إلا أنها نسبة

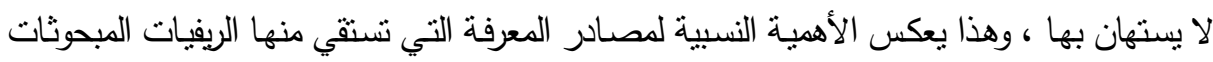
معارفهن في مجال الحد من أخطار تلوث البيئة بالمبيدات.

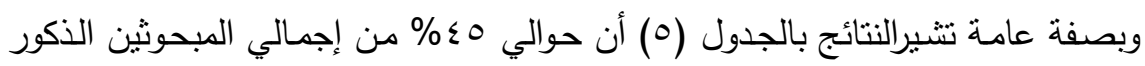

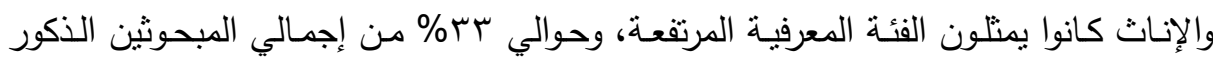

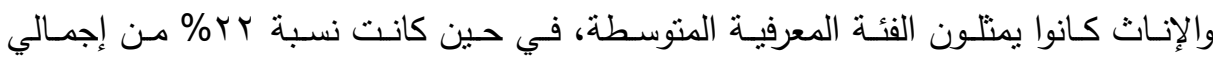
المبحوثين الذكور والإناث يمتلون الفئة المعرفية المنخفضة. 
وبإختبار معنوية العلاقه بين كلا من معارف المبحوثين بالتوصيات الفنية المتعلقة بالحد من أخطار تلوث البيئة بالمبيدات بين الذكور والاناث اتضـح أن العلاقة معنوية عند مسنوى ل ب.,.

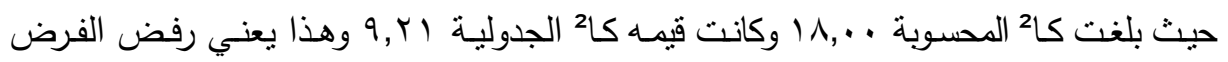
الإحصائي وقبول الفرض البديل. ثالثا: مستوى معرفة المبحوثين (الذكور والإناث) بالممارسات التتفيذية المتعلقة بالحد من أخطار تلوث البيئة بالمبيدات في منطقة الاراسة: أوضحت النتائج جدول رقم (7) انه يمكن ترتيب الممارسات المتعلقة بالحد من أخطار

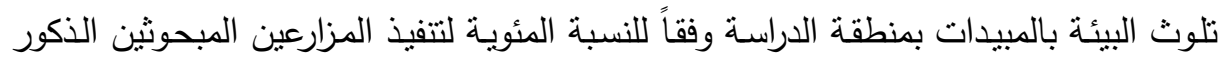

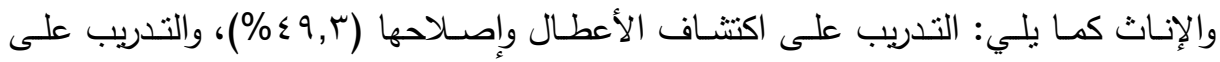

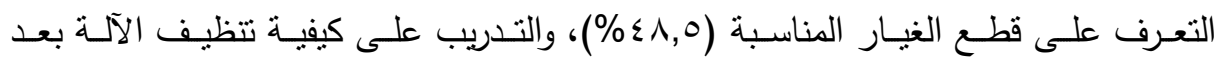

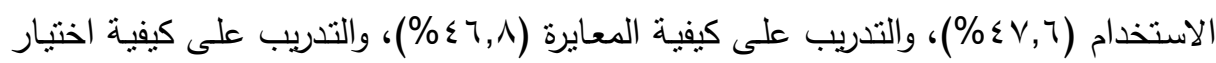

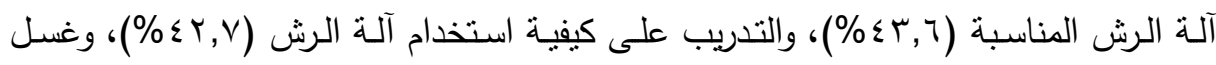
الملابس بالماء الساخن بعد انتهاء الرش ( ( , ــ\%)، ودفن العبوات الفارغة للمبيد في مكان

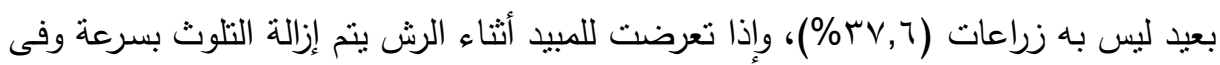

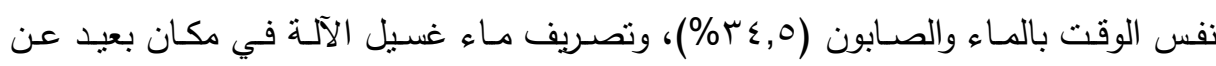

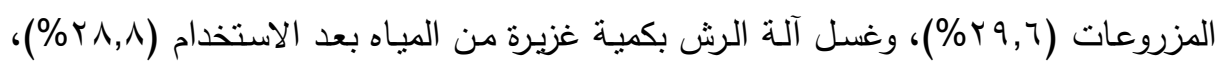

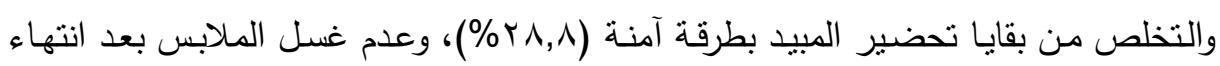

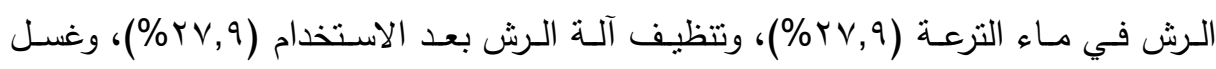

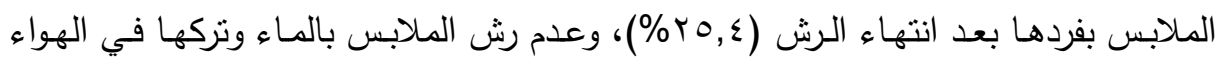

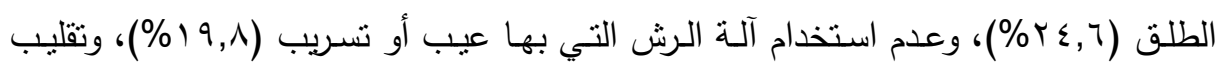

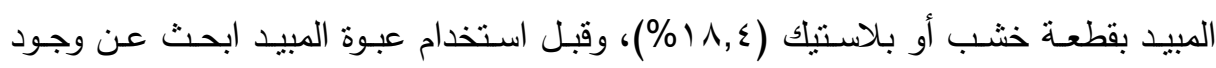

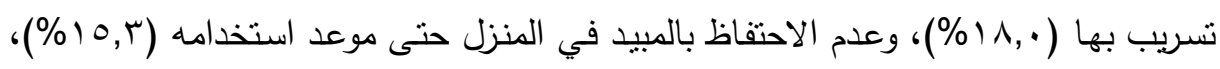

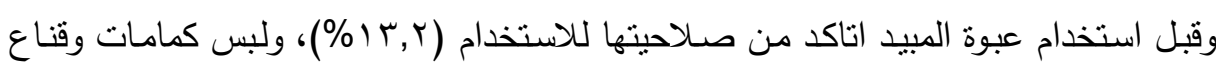

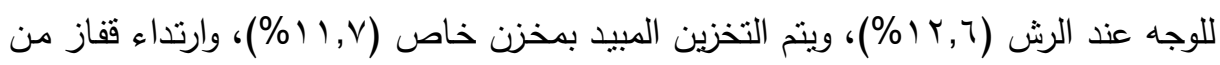




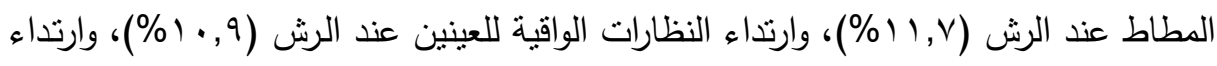
ملابس خاصـة للرش (9, • (\%\%)، وقراءة المعلومـات الموجودة على ملصـق البيانـات بعبوة

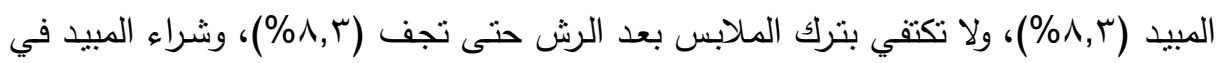

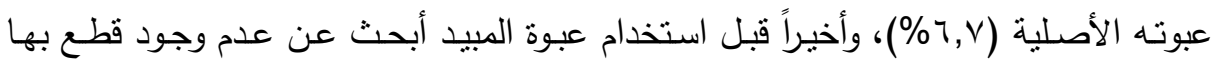
$\cdot(\% 0,9)$ 
جدول رقم(؟): توزيع المبحوثين وفقاً لتنفيذهم للممارسات المتعلقة بالحد من أخطار تلوث البيئة للمبيدات بمنطقة الدراسة

\begin{tabular}{|c|c|c|c|}
\hline $\begin{array}{c}\% \\
|r|=\dot{0}\end{array}$ & عدد & 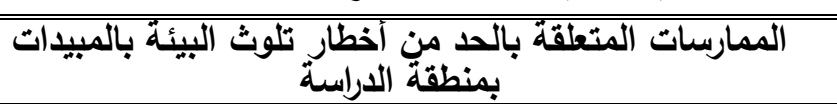 & م \\
\hline $0 \wedge, \vee$ & (v) & شراء المبيد في عبوته الأصلية & 1 \\
\hline $91, \mathrm{~V}$ & 111 & عدم الاحتفاظ بالمبيد في منزله حتى موعد استخدامه & $r$ \\
\hline $79, \xi$ & $\Lambda \varepsilon$ & يتم تخزين المبيد بمخزن خاص & r \\
\hline 09,0 & $\overline{V T}$ & قراءة المعلومات الموجودة على ملصق الييانات بعبوة المييد & $\varepsilon$ \\
\hline 71,7 & $\overline{\Delta N}$ & عدم استخدام آلة الرش التي بها عبب أو تنسريب & $\overline{0}$ \\
\hline$V \uparrow$, & 94 & التدريب على كيفية استخدام آلة الرش & 7 \\
\hline$\nabla \wedge, 0$ & 90 & التثريب على كيفية اختبار اللة الرش المناسبة & $\bar{V}$ \\
\hline$\nabla 9, \Gamma$ & 97 & التثريب على كيفية المعايرة & $\Lambda$ \\
\hline$\Lambda \cdot, 9$ & 91 & التدريب على كيفية تتظبف الآلة بعد الاستخدام & 9 \\
\hline$\Lambda \cdot, r$ & $9 \mathrm{~V}$ & التنريب على التعرف على قطع الغيار المناسبة & T. \\
\hline$\Delta Y, T$ & $1 \ldots$ & التذربب على اكتثاف الآعطال واصلاحها & 11 \\
\hline $79, \varepsilon$ & $\Lambda \varepsilon$ & ارتداء قفاز من المطاط عند الرش & $T$ \\
\hline$V 1,9$ & AV & لبس كمامات وقناع للوجه عند الرش & 14 \\
\hline$\vee 1,1$ & $\Lambda 7$ & ارتداء النظارات الواقية للعينين عند الرش & $1 \leqslant$ \\
\hline$V Y, V$ & $\Lambda \Lambda$ & ارتداء ملابس خاصة للرش & 10 \\
\hline 77,9 & AI & غسل الملابس بمفردها بعد الانتهاء من الرش & 17 \\
\hline $70, \pi$ & $\mathrm{vq}$ & غسل الملابس بالماء الساخن بعد الانتهاء من الرش & IV \\
\hline $71, Y$ & $\mathrm{~V} \varepsilon$ & عدم غسل الملابس بعد الاتنهاء من الرش في ماء التزعة & 11 \\
\hline 77,9 & AI & عدم ش الملابس بالماء وتركها في الهواء الطلق & 19 \\
\hline 09,0 & $\overline{V Y}$ & لا نكتفى بترك الملابس بعد الرش حتى تجف & $r$. \\
\hline $7 V, \Lambda$ & Ar & إذا تعرضت للمبيد أثثاء الرش بتث إزالة التلوث بسرعة وفى نفس الوقت بالماء والصابون & YI \\
\hline $0 \wedge, V$ & V) & قبل استخداح عبوة المبيد ابحث عن عدم وجود قطع بها & $\overline{Y Y}$ \\
\hline 09,0 & VY & قبل استخدام عبوة المبيد ابحث عن وجود تسريب بها & $\overline{T H}$ \\
\hline 77,9 & A) & قبل استخدام عبوة المبيدات التأكد من صلاحيتها للاستخدام & TI \\
\hline$V \vee, V$ & $9 \varepsilon$ & تقليب المبيد بقطعة خشب أو بلاستيك & Yo \\
\hline $79, \varepsilon$ & $\Lambda \varepsilon$ & تتظيف آلة الرش بعد الأستخدام & Y7 \\
\hline $7 \wedge, 7$ & $\Delta \mu$ & غسل آلة الرش بكمية غزيرة من المياه بعد الاستخدام & TV \\
\hline$(1,1$ & Aт & تصريف ماء غسيل الآلة في مكان بعيد عن المزروعات & rA \\
\hline 71,7 & $\Delta r$ & التخلص من بقايا تحضير المبيد بطريقة آهنة & rq \\
\hline $7 r, \Lambda$ & V7 & دفن العبوات الفارغة للمبيد في مكان بعيد & $\Gamma$. \\
\hline$V \cdot, Y_{O}$ & 10 & متوسط درجة التتفيذ & \\
\hline
\end{tabular}


ويالنسبة لتحديد الفروق بين المبحوثين من الذكور والإناث وفقاً لفئات تنفيذهم للممارسات المتعلقة بالحد من أخطار تلوث البيئة بالمبيدات بمنطقة الدراسة:

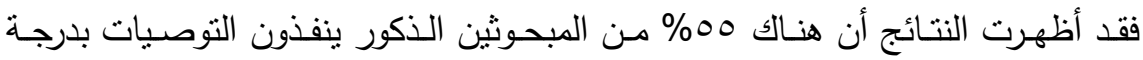

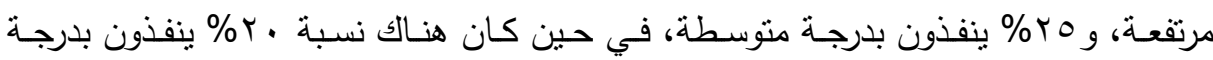

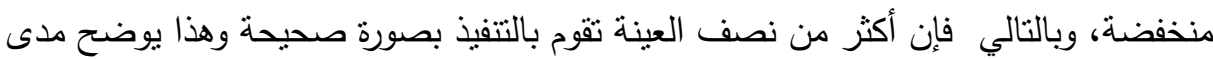

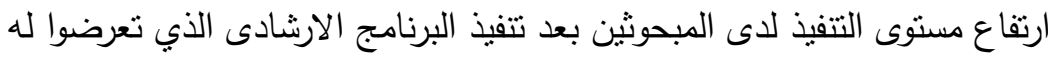

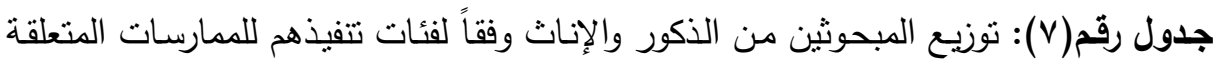
بالحد من أخطار تلوث البيئة بالمبيدات بمنطقة الدراسة

\begin{tabular}{|c|c|c|c|c|c|c|}
\hline \multicolumn{6}{|c|}{ توزيـع المبحوثُنين } & \multirow{4}{*}{ فئات التنفيذ } \\
\hline \multicolumn{6}{|c|}{ عدد } & \\
\hline \multicolumn{2}{|c|}{ إجمالى } & \multicolumn{2}{|c|}{ إناث } & \multicolumn{2}{|c|}{ ذكور } & \\
\hline$\%$ & عدد & $\%$ & عدد & $\%$ & عدد & \\
\hline YT & 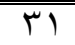 & Tा & 11 & r. & $1 \pi$ & تنفيذ منغفض (صفر - . ادرجات) \\
\hline$\mu \wedge$ & $\sum 7$ & Or & $\mu$. & TO & 17 & تنفيذ متوسط(1) - بدرجة) \\
\hline T4 & $\varepsilon \varepsilon$ & 17 & 9 & 00 & ro & تتفيذ مرتفع( ا - . "זدرجة) \\
\hline $1 \cdots$ & $|T|$ & $1 \ldots$ & OV & $1 \ldots$ & $7 \varepsilon$ & مجموع \\
\hline
\end{tabular}

المصدر: جمعت وحسبت البيانات من نتائج الاستنيان.

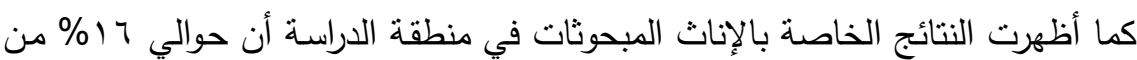

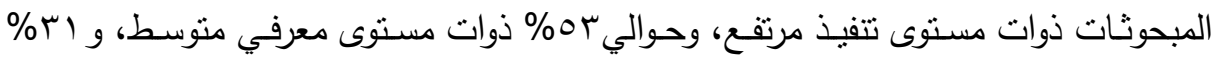

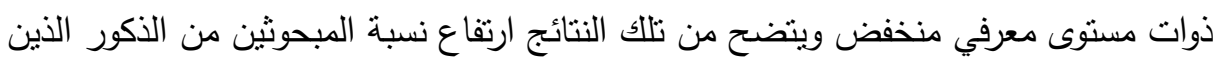

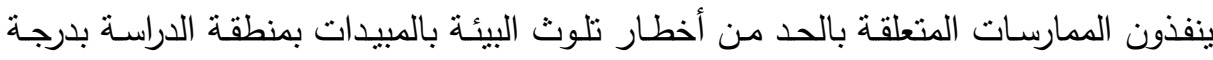

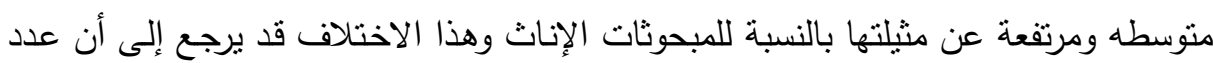

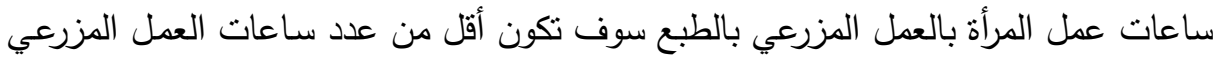

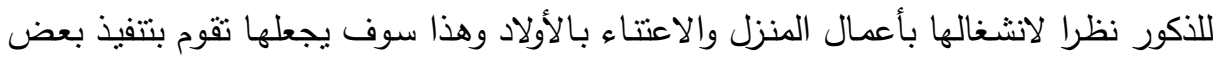
الممارسات و ليست كل الممارسات مقارنة بالذكور .

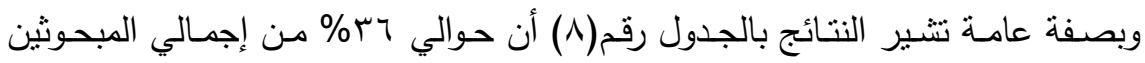

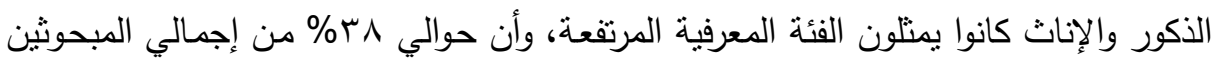


الذكور والإناث كانوا يمنلون الفئة المعرفية المتوسطة، في حين كان حوالي بr\% من إجمالي المبحوثين الذكور والإناث يمثلون الفئة المعرفية المنخفضة.

وباختبار معنويـة العلاقـة بين المبحوثين الذكور والإنـاث لتتفيذهم للممارسـات المتعلقة

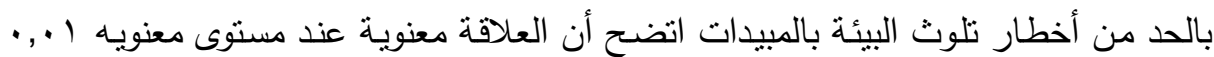

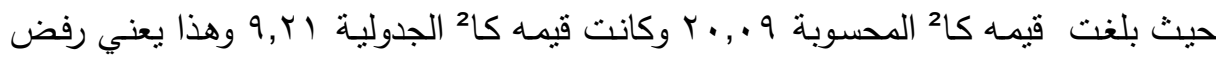
الفرض الإحصائي وقبول الفرض البديل.

\section{التموصيامث}

ا-وفقا لما أوضحته نتائج الدراسة من وجود تباين في مستويات المعرفة بالأساليب المختلفة للحفاظ على البيئة، مما يتطلب التتسيق من جهاز الإرشاد الزراعي وجهاز شؤون البيئة

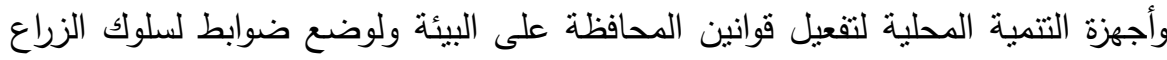
الضار بالبيئة ولحماية الموارد الارضيه والمائية من التلوث.

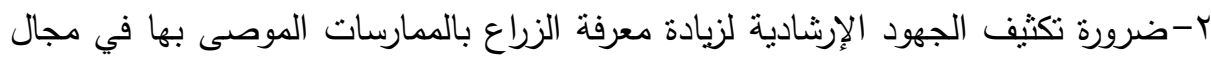
الحد من تدهور البيئة بصفة عامة وبصفة خاصة في مجال الحد من أخطار تلوث البيئة بالمبيدات والتي أوضحتها نتائج الدراسة ومن أهمها معرفة اسباب التلوث البيئي، التاثير

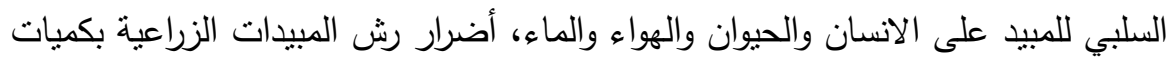

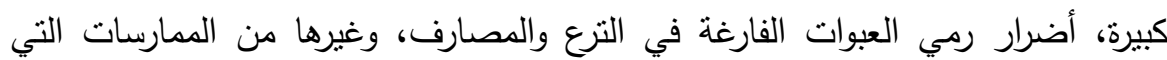

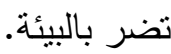
r-إكساب الزراع المعارف والمهارات المتعلقة بإنتاج محاصيل خالية من الملوثات اعتمادا

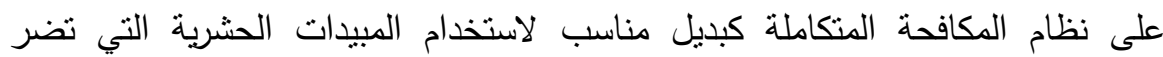
بالإنسان والمنظومة البيئية. ع- النتائج اظهرت ان هناك مشاركة كبيرة للمرأة الريفية في البرنامج حيث بلغت نسبتها (\%乞 \&,^) 
للرجل في العمل المزرعي عن طريق إعداد البرامج الإرشادية المختلفة التي تلبي

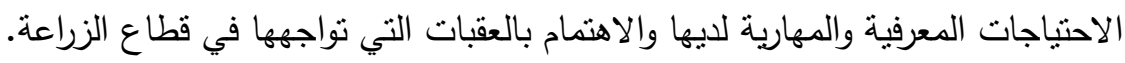
0-زيادة معدل العمل الإرشادي الموجه للمرأة الريفية فيما يتعلق بالوعي البيئي ومعرفتهن

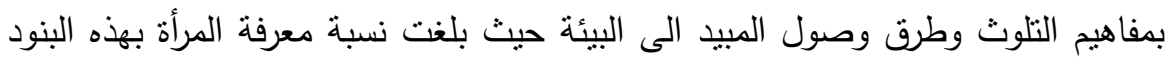

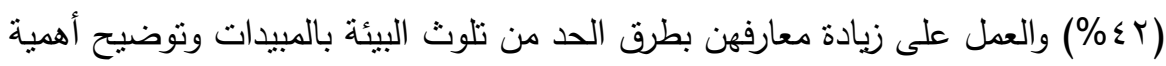
وخطورة المشكلة والنتائج المترتبة على ذلك.

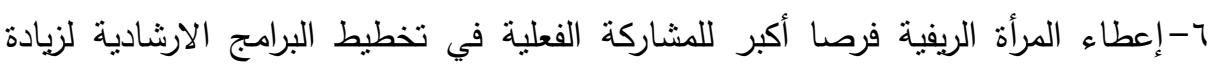
فرص الاتصال بين المرأة الريفية ومسؤلي التتمية في المنظمات المحلية الموجودة بالقرية.

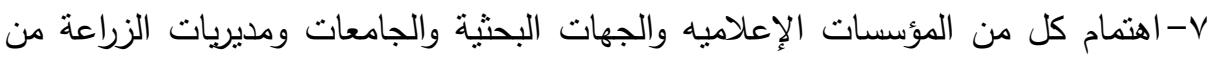
أجل زيادة مصادر المعلومات للحد من تلوث البيئة بالمبيدات.

\section{المرالم:}

جهاز شئون البيئة، وزارة الدوله لثئون البيئة، ثقرير عن حالة البيئة في مصر ، ه. .ب.

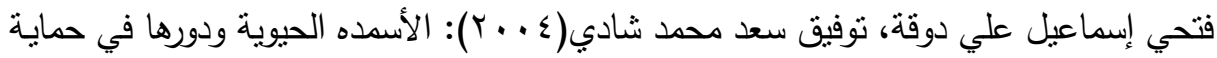

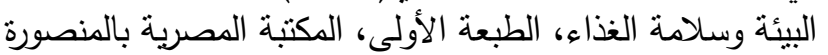

زهران، محمود عبد القوي( · . . †): الإسلام والبيئة، المكتبة الأكاديمية بالجيزة، مصر 


\title{
FARMERS KNOWLEDGE LEVEL ABOUT PRACTICES THAT REDUCE ENVIRONMENT POLLUTION RISK WITH PESTICIDES IN SOME VILLAGES OF TOOKH DISTRICT, QALIUBIYA GOVERNORATE
}

El Zimaity, M. E. ${ }^{(1)}$; Swailam, M.N. A. ${ }^{(2)}$; El-Rafei, M. M. K. ${ }^{(3)}$ and Heikal, Wafaa, H. S. ${ }^{(4)}$

1) Faculty of Agriculture, Ain Shams University 2) Faculty of Agriculture, Al Azhar University 3) Institute of Environmental Studies and Research, Ain Shams University 4) Agriculture Extension \& Rural Development Research Institute, Agricultural Research Center.

\begin{abstract}
The study aims to identify the knowledge level of the respondents males and females) regarding the technical recommendations related to reducing the risk of environment pollution with pesticides in "Tookh" District Qaliubiya governorate. The study focused on identifying the personal and social characteristics of the interviewees, and identifying the differences between respondents (males and females) with respect to both their knowledge level of the agricultural technical recommendations and their level of knowledge of the implemented practices. The stuck $\|$ as carried oast in "ELManzala". "Namool" and "Terrsah" villages with a total random sample of 121 respondents (64 male and 57 female).

Data were collected using personal interview questionnaire, and analyzed using appropriate statistical methods. The most important results of the study can he summarized as follows: Females' participation in the suggested extension program was

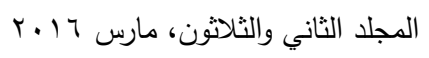


محمد السعيد صالح الزميتي وآخرون

high representing about (47.1\%). Males had high knowledge level regarding the technical recommendations of reducing environment pollution with pesticides. whereas (20\%) of them had medium knowledge level. and (17\%) had Low level. Females' knowledge level was high representing about (25\%). and about $(47 \%)$ had medium level, and $(28 \%)$ had low knowledge level. The results revealed that about $45 \%$ of total respondents $(\mathrm{M} / \mathrm{F})$ fell in the high knowledge category of the technical recommendations. $33 \%$ fell in the medium category and finally $22 \%$ fell in the loll category.

By testing the significance of the relationship between both of the respondents knowledge of the technical recommendations among males and females. it was apparent that the relationship was significant at the level of (0.01). where calculated Chi' reached (18.00) and the tabulated reached (9.21). Regarding the implementation degree of technical recommendations, about 55\% of males had high implementation degree, whereas $25 \%$ and $20 \%$ had medium and low implementation degree respectively. In general half of the sample implemented the extension program effectively.

Additionally, the results showed that about $16 \%$ of females had high implementation level and about 53\% of them had medium level. while $31 \%$ had low implementation level. Generally. about $36 \%$ of the total respondents had high implementation level. 38\% had medium level, 26\% low level. By testing the significance of the relationship between male and female respondents regarding their implementation practices to reduce the environment pollution with pesticides. it was revealed that the relationship was significant at level of (0.01). as the value of calculated Chi- was (20.09) and the tabulated value was (9.21).

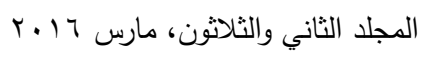

